\title{
Conjunctive management of surface and groundwater resources under projected future
}

climate change scenarios

Amir Mani ${ }^{1}$, Frank T.-C. Tsai ${ }^{2,}$, Shih-Chieh Kao ${ }^{3}$, Bibi S. Naz ${ }^{4}$, Moetasim Ashfaq ${ }^{5}$, and

Deeksha Rastogi 6

${ }^{1}$ Graduate Student, Department of Civil and Environmental Engineering, Louisiana State 9 University, 3526G Patrick F. Taylor Hall, Baton Rouge, Louisiana, 70803, USA, Phone: 1-225-

10 578-4246, Email: amani1@1su.edu

${ }^{2}$ Professor, Department of Civil and Environmental Engineering, Louisiana State University, 3526G Patrick F. Taylor Hall, Baton Rouge, Louisiana, 70803, USA, Phone: 1-225-578-4246, Email: ftsai@1su.edu

${ }^{3}$ Research Scientist, Environmental Sciences Division and Climate Change Science Institute, Oak Ridge National Laboratory, Oak Ridge, TN 37831, Email: kaos@ ornl.gov

${ }^{4}$ Post-doctoral Research Associate, Environmental Sciences Division and Climate Change Science Institute, Oak Ridge National Laboratory, Oak Ridge, TN 37831, Email: naz.bibi2007@gmail.com

${ }^{5}$ Research Scientist, Computer Science and Mathematics Division and Climate Change Science Institute, Oak Ridge National Laboratory, Oak Ridge, TN 37831, Email: mashfaq@ ornl.gov

${ }^{6}$ Post-graduate Research Associate, Computer Science and Mathematics Division and Climate Change Science Institute, Oak Ridge National Laboratory, Oak Ridge, TN 37831, Email: rastogid@ornl.gov

*Corresponding Author

This manuscript has been co-authored by employees of Oak Ridge National Laboratory, managed by UT Battelle, LLC, under contract DE-AC05OOOR22725 with the U.S. Department of Energy. The United States Government retains and the publisher, by accepting the article for publication, acknowledges that the United States Government retains a non-exclusive, paid-up, irrevocable, world-wide license to publish or reproduce the published form of this manuscript, or allow others to do so, for United States Government purposes. The Department of Energy will provide public access to these results of federally sponsored research in accordance with the DOE Public Access Plan (http://energy.gov/downloads/doe-public-access-plan). 


\section{Abstract}

This study introduces a mixed integer linear fractional programming (MILFP) method to

41 optimize conjunctive use of future surface water and groundwater resources under projected

42 climate change scenarios. The conjunctive management model maximizes the ratio of

43 groundwater usage to reservoir water usage. Future inflows to the reservoirs were estimated from

44 the future runoffs projected through hydroclimate modeling considering the Variable Infiltration

45 Capacity model, and 11 sets of downscaled Coupled Model Intercomparison Project phase 5

46 global climate model projections. Bayesian model averaging was adopted to quantify uncertainty

47 in future runoff projections and reservoir inflow projections due to uncertain future climate

48 projections. Optimized conjunctive management solutions were investigated for a water supply

49 network in northern Louisiana which includes the Sparta aquifer. Runoff projections under

50 climate change scenarios indicate that runoff will likely decrease in winter and increase in other

51 seasons. Results from the developed conjunctive management model with MILFP indicate that

52 the future reservoir water, even at $2.5 \%$ low inflow cumulative probability level, could

53 counterbalance groundwater pumping reduction to satisfy demands while improving the Sparta

54 aquifer through conditional groundwater head constraints.

56 Keywords: Conjunctive use, Multi-reservoir system, Groundwater, Climate Change,

57 Uncertainty, Fractional programming 


\section{Introduction}

Sustainable planning and management of limited water resources has become a critical

60 issue in light of decreasing water availability, increasing water demands, and imbalance use of

61 surface water and groundwater. Water resources sustainability largely depends on proper

62 management and efficient utilization of water (Fasakhodi et al., 2010). Conjunctive use of

63 surface water and groundwater resources provides a long-term solution for improving water use

64 efficiency (Singh, 2014).

65 However, managing future water resources often presents challenges due to uncertain

66 future precipitation and runoff projections. Hydrometeorological variability is likely to increase

67 in the near term (through 2050), leading to more intense, frequent climate events (Mahoney et

68 al., 2012). Uncertainty and variability increases the complexity of the problems water resources

69 decision makers face (Najafi et al., 2011). Due to the inherent uncertainty in modeling, it is very

70 important to ensure the robustness of potentially expensive, irreversible adaptation decisions

71 (Bastola et al., 2011).

72 Regional water resources undergoing climate change are typically studied through the

73 modeling chain (Bosshard et al., 2013), which includes elements such as (1) global circulation

74 models (GCMs), (2) future greenhouse gas emission (GHG) scenarios or representative

75 concentration pathways (RCPs), (3) downscaling methods, and (4) hydrological models.

76 Hydroclimate modeling can address (1) the impacts of future climate change, (2) the undefined

77 effects of climate change on the availability of water resources, and (3) the resilience of water

78 resources management (Bastola et al., 2011). The Intergovernmental Panel on Climate Change

79 (IPCC) Fifth Assessment Report (AR5) suggested using multimodel ensembles for detection,

80 attribution, impact, and adaptation studies (Stocker et al., 2010). It is evident that the uncertainty 
81 across different climate models is relatively larger than other sources of uncertainties (Weiland et

82 al., 2012). Therefore, for water resources planning, the multimodel ensemble approach will be a

83 more appropriate method than relying on a single model. Multimodel ensemble approaches

84 exploit the diversity of multiple competent modeling chains and their advantages in describing

85 hydrologic processes. This study adopts Bayesian model averaging (BMA) (Hoeting et al., 1999)

86 as a multimodel ensemble method to account for projected inflow uncertainty for the

87 conjunctive-use modeling under climate change projection uncertainty. BMA accounts for model

88 uncertainty by producing a weighted probability density function using the posterior probability

89 of each participating model while better performing predictions receive higher weights (Min et

90 al., 2007; Liang et al., 2013). BMA has been applied to uncertainty analysis in weather

91 forecasting and hydrologic prediction (Ajami et al., 2006; Duan et al., 2007; Min et al., 2007;

92 Vrugt et al., 2007; Zhang et al., 2009; Dong et al., 2013), and climate change impact analysis

93 (Raftery and Zheng, 2003; Tebaldi et al., 2005; Buser et al., 2009; Smith et al., 2009; Liang et

94 al., 2013).

95 Although projecting future runoff and quantifying its underlying uncertainty have been

96 studied extensively in the literature, little work has been done to incorporate these results in

97 future decision making for the conjunctive management of surface water and groundwater

98 resources. Coupled simulation-optimization models have been used extensively for conjunctive

99 management of groundwater and surface water resources, as indicated in the literature for

100 complex water allocation problems. These coupled simulation-optimization models have aided in

101 developing sustainable operational strategies (Mantoglou, 2003; Bhattacharjya and Datta, 2005;

102 Ramesh and Mahesha, 2008; Bazargan-Lari et al., 2009; Mohammad Reazpour Tabari et al.,

103 2014). For groundwater and multi-reservoir management, linear programming (LP), dynamic 
104 programming (DP), and genetic algorithm (GA) are the most commonly applied optimization 105 approaches (Singh, 2012). Katsifarakis and Petala (2006) implemented both LP and differential 106 evolution (DE) to manage a coastal karstic groundwater aquifer. Tamer Ayvaz and Karahan 107 (2008) compared the performance of LP, NLP, DP, and GA in identifying unknown groundwater 108 pumping well locations and pumping rates. The studies concluded that all optimization methods 109 yield comparable results, while LP acquires the least computational expense and calculation 110 time.

111 This study introduces a mixed integer linear fractional programming (MILFP) method for 112 the conjunctive use of surface water and groundwater under uncertain future inflow projection. 113 Fractional programming (FP) is the optimization of a ratio of two functions (Schaible, 1981). FP 114 naturally addresses a multi-objective management problem by maximizing the benefit-cost ratio 115 in water resources planning and management (Lara and Stancu-Minasian, 1999; Amini 116 Fasakhodi et al., 2010; Zhu and Huang, 2011; Ren et al., 2013; Guo et al., 2014). MILFP is a 117 linear form of FP with integer decision variables, which optimizes the ratio of two mixed integer 118 linear objective functions subject to mixed integer linear constraints. Due to its ability to be 119 transformed to a mixed integer linear program (MILP), MILFP provides a computationally 120 simple and efficient optimization framework to maximize one objective while minimizing its 121 effect on resources through its ratio objective function.

122 In the following sections, MILFP is developed for a conjunctive-use study of surface 123 water and groundwater for the Sparta aquifer in the northern Louisiana, USA. This study uses a 124 hybrid downscaling method to develop future climate change scenarios based on 11 Coupled 125 Model Intercomparison Project Phase 5 (CMIP5) GCMs. The downscaled precipitation and 126 temperature are used as inputs to the Variable Infiltration Capacity (VIC) model (Liang et al., 
127 1994) to project future natural runoff and reservoir inflow. The BMA is used to estimate the

128 ensemble inflow to reservoirs. The projected demand withdrawals from reservoirs and

129 groundwater pumping rates are then presented and discussed.

\section{2. Methodology}

\section{$131 \quad$ 2.1. Study Area}

132 The Sparta aquifer shown in Fig. 1a is the major source of water supply for Arkansas and 133 northern Louisiana (McKee and Clark, 2003). From 1980 to 2010, the groundwater from the

134 aquifer in northern Louisiana was withdrawn at a rate of 246,052 to $264,979 \mathrm{~m}^{3} / \mathrm{day}$, or $\sim 65$ to 13570 million gallons per day (MGD) (Sargent, 2012). Over pumping has caused the groundwater 136 level to decline by an average of 0.3 to $0.9 \mathrm{~m} / \mathrm{year}$ ( 1 to $3 \mathrm{ft} / \mathrm{year}$ ), and it has also caused 137 saltwater intrusion (McKee and Clark, 2003). Areas with groundwater levels below the top of the 138 Sparta aquifer are of particular concern (LaDNR, 2015). A wastewater treatment facility (Sparta 139 Re-use Facility in West Monroe) was contructed to conserve the Sparta aquifer. Since 2013, the 140 facility has offset groundwater pumping by $\sim 18,927 \mathrm{~m}^{3} /$ day (5 MGD), providing reclaimed water 141 to a major industrial user. Four reservoirs-Bayou D’Arbonne Lake, Lake Claiborne, Corney 142 Lake, and Lake Bistineau (Fig. 1a)—supply fresh water to major cities in northern Louisiana 143 (Meyer et al., 2002). These reservoirs are used primarily for recreation (US Army Corps of 144 Engineers [USACE], 2015). Three reservoirs are located in the Bayou D'Arbonne subbasin (US 145 Geological Survey [USGS] 8-digit hydrologic unit code [HUC8] 08040206), and another 146 reservoir is in the Loggy Bayou subbasin (HUC8 - 11140203).

[Figure 1]

\section{$148 \quad$ 2.2. Conjunctive Surface Water and Groundwater Allocation Model}


To assess the effect of climate change on planning and management of reservoir

150 operations and groundwater pumping, a conjunctive management model (Fig. 2) is developed

151 based on fractional programming. It links a groundwater model and a hydrologic model. The

152 objectives are to maximize groundwater withdrawal and to minimize reservoir storage deficit

153 subject to a water balance equation for network flow, water demand constraints, and

154 groundwater head constraints. Specifically, future reservoir inflow projections are derived from

155 the VIC model given downscaled climate projections. BMA is adopted to derive ensemble mean

156 and variance of reservoir inflows. Detailed information for the conjunctive management model is

157 provided as follows.

[Figure 2]

The water supply network for northern Louisiana (Fig. 1b) includes six major cities:

160 Farmerville (node $\mathrm{D}_{1}$, Union Parish), Monroe (node $\mathrm{D}_{2}$, including West Monroe in Ouachita

161 Parish), Ruston (node $\mathrm{D}_{3}$, Lincoln Parish), Arcadia (node $\mathrm{D}_{4}$, Bienville Parish), Homer (node $\mathrm{D}_{5}$,

162 Claiborne Parish), and Minden (node $\mathrm{D}_{6}$, Webster Parish). Their average monthly water demands

163 are shown in Table 1 (Sargent, 2012). Farmerville and Monroe are designed to receive

164 groundwater and surface water from Bayou D'Arbonne Lake (node $\mathrm{S}_{2}$ ) located downstream from

165 Corney Lake (node $\mathrm{S}_{1}$ ) and Lake Claiborne (node $\mathrm{S}_{3}$ ). The Sparta Re-use Facility has provided

$16618,927 \mathrm{~m}^{3} /$ day (5 MGD) to Monroe since 2013. Ruston is designed to receive groundwater and 167 surface water from Bayou D’Arbonne Lake, Lake Claiborne (node $\mathrm{S}_{3}$ ), and Lake Bistineau (node $168 \mathrm{~S}_{4}$ ). Arcadia, Minden, and Homer are near or in the recharge zone of the Sparta aquifer and are 169 designed to use surface water only. The water demands and reclaimed water supply are assumed 170 to be constant throughout the study. 
173 Ouachita parish (four pumping centers for Monroe, node $\mathrm{W}_{2}$ ), Union parish (one pumping center

174 for Farmerville, node $\mathrm{W}_{1}$ ) and Lincoln parish (one pumping center for Ruston, node $\mathrm{W}_{3}$ ).

175 Multiple USGS observation wells are shown Fig. 1a. To restore the Sparta aquifer to its 176 predevelopment condition, this study assigns the 1975 groundwater level as the target

177 groundwater level at four USGS observation wells in Ouachita, and it assigns 1985 groundwater 178 level as the target level at one USGS observation well in Lincoln and another in Union. Pumping 179 rates from other smaller wells in northern Louisiana are assumed to remain unchanged.

180 The network conjunctive water use model is simulated at monthly time steps. The 181 maximum and minimum reservoir storages are the physical limits from the USACE National 182 Dam Inventory (USACE, 2015). Not all reservoirs are regulated for high flow seasons due to 183 their recreational use. No capacity limit is given to the arcs in the proposed water supply 184 network. The lower bound of reservoir spill is assigned to be zero due to the lack of 185 environmental flow information. Evaporation from reservoir surface and groundwater exchange 186 along the reservoir boundaries is also assumed to be negligible due to lack of data.

187 2.3. Hydrologic Modeling

188 To simulate the natural inflow to reservoirs, the semi-distributed VIC hydrologic model 189 (Liang et al., 1994; 1996) is used. VIC is a process-based hydrological model that simulates 190 evapotranspiration, snow pack, surface runoff, baseflow, and other hydrologic mechanisms 191 within a watershed. Within each grid cell, the water and energy balances are solved for multiple 192 elevation bands and vegetation types, allowing the model to capture the subgrid variability of 193 these land surface features. An external two-dimensional horizontal routing algorithm can then 194 be used to estimate streamflow at a specified location (Lohmann et al., 1998). The VIC model is 
195 widely used for climate change impact assessment and can be used for either single basins (e.g.,

196 Christensen et al., 2004) or continental-scale studies (e.g., Vetter et al., 2015; Hagemann et al.,

197 2013). However, it should also be noted that the current version of VIC model does not simulate

198 groundwater.

199 Pre-organized VIC input data from Oubeidillah et al. (2014) are used to simulate surface

200 hydrology for Bayou D’Arbonne (HUC8 - 08040206) and Loggy Bayou (HUC8 - 11140203)

201 subbasins. The VIC model is implemented at $1 / 24^{\circ}(\sim 4 \mathrm{~km})$ grid cell resolution with three-hour

202 time steps. Five elevation bands are considered to incorporate the variability within the grids in

203 precipitation and elevation. Based on the aggregated elevation from the National Elevation

204 Dataset (NED) (Gesch et al., 2002) and also flow direction from the National Hydrography

205 Dataset Plus (NHDPlus) (USEPA and USGS, 2010), flow direction grids in northern Louisiana

206 are further generated for streamflow routing to the locations of reservoirs, and multiple USGS

207 gauges. Oubeidillah et al. (2014) provide further details on VIC model setup, input parameters,

208 and model calibration.

209 To evaluate the performance of VIC model, a control run simulation is conducted by using

210 the Daymet dataset (Thornton et al., 1997) as the driving meteorological forcings. Both

211 simulated total runoff (i.e., baseflow plus surface runoff) and routed streamflow were compared

212 to the USGS WaterWatch runoff dataset (Brakebill et al., 2011) and the National Water

213 Information System (NWIS) gauge observation (Fig. 3). In general, VIC-simulated total runoff

214 for both subbasins shows strong similarity to the USGS WaterWatch runoff shown in Fig. 3a-b.

215 Although runoff in the Loggy Bayou subbasin showed larger bias (NSE = 0.55), runoff in the

216 Bayou D’Arbonne subbasin was well simulated (NSE $=0.80)$, suggesting that the overall surface

217 water balance is reasonably simulated. Similarly, VIC-simulated streamflow at Bayou Dorcheat 
218 near Springhill, LA (in Loggy Bayou subbasin), and at Little Corney Bayou near Lillie, LA (in

219 Bayou D'Arbonne subbasin), also match well with the observed streamflow shown in Fig. 3c-d.

220 The locations of the two streamflow gauges are shown in Fig. 1a. The VIC model is then used to 221 simulate the projected future reservoir inflow under multiple sets of future climate change 222 projections (see Sect. 2.6).

[Figure 3]

\section{2.4. Groundwater Modeling}

The USGS Sparta groundwater model (McKee and Clark, 2003) is adopted to simulate

226 groundwater head in the Sparta aquifer from 1980-2010. Future pumping rates for 2011-2025

227 are assumed to be the same as 2010 pumping rates. McKee and Clark (2003) describes detailed

228 model development. The monthly groundwater head is simulated, while the yearly groundwater

229 pumping rates are optimized. This yields a $90 \times 90$ response matrix for the successive MILP

230 problem. This study adopts the one-side finite difference method to calculate the sensitivities

231 using 91 MODFLOW parallel runs on a supercomputer at Louisiana State University.

\section{2.5. Fractional Programming for Conjunctive Management}

233 To balance the use between surface water from reservoirs and groundwater from

234 pumping, a conjunctive management model is proposed based on fractional programming. The

235 proposed conjunctive management model aims to maximize the ratio of two competing

236 objectives, total groundwater withdrawal to the total deficit of reservoir storages with respect to

237 their maximum storages. Because groundwater is generally cheaper and its quality is generally

238 better than reservoir water, maximizing the ratio will maximize groundwater usage and minimize

239 reservoir storage loss. This is especially important for reservoirs not used for flood control. To

240 keep aquifers for sustainable use, the study imposes groundwater head constraints at several 
241 control points, thus limiting groundwater withdrawal. The demand deficit caused by limiting

242 groundwater pumping can be offset by using the reservoir water. The conjunctive management

243 model is formulated as the following nonlinear fractional programming problem:

$$
\operatorname{Maximize} \frac{\sum_{n} \mathbf{1}^{T} \mathbf{Q}_{n}}{\sum_{t} \mathbf{1}^{T}\left(\mathbf{S}_{\max }-\mathbf{S}_{t}\right)+\beta},
$$

245 subject to

$$
\left\{\begin{array}{lll}
\mathbf{h}_{t+1} \geq \mathbf{h}_{t}+\boldsymbol{\Delta}_{1} & \text { if } & \mathbf{h}_{t}<\mathbf{h}^{\text {target }} \\
\mathbf{h}_{t+1} \geq \mathbf{h}_{t}-\boldsymbol{\Delta}_{2} & \text { if } & \mathbf{h}_{t} \geq \mathbf{h}^{\text {target }}
\end{array}\right.
$$

252 The vector $\mathbf{X}$ includes all state and decision variables:

$253 \mathbf{Q}_{n}$, the vector of groundwater pumping rate for different pumping wells during stress period $n$,

$254 \mathbf{S}_{t}$, the vector of storage for different reservoirs at time $t$,

$255 \mathbf{R}_{t}$, the vector of demand withdrawal from different reservoirs during time period $t$,

$256 \mathbf{S} \mathbf{p}_{t}$, the vector of spill from different reservoirs during time period $t$, and

$257 \mathbf{x}_{t}$, the vector of water flow in a water supply network during time period $t$.

$258 \mathbf{X}_{\min }$ and $\mathbf{X}_{\max }$ are the vectors of the lower and upper bounds of the variables. 
$259 \mathbf{h}_{t}$ is the vector of groundwater head at control locations at time $t$, which is a function of the 260 pumping rate $\mathbf{Q}_{n}$.

$261 \mathbf{h}^{\text {target }}$ is the vector of target groundwater head at control locations.

$262 \Delta_{1}$ and $\Delta_{2}$ are the policy parameters, which are non-negative coefficients.

$263 \mathrm{I}_{t}$ is the vector of natural inflow to reservoirs during time period $t$.

$264 \mathbf{E}_{t}$ is the vector of evaporation from reservoir surface during time period $t$.

$265 \mathbf{b}_{t}$ is the source/sink nodes in the water supply network during time period $t$.

$266 \beta=1$ is a non-negative constant to prevent the denominator value from being a very small 267 number.

$268 T$ is the transpose operator.

2691 is the vector of ones.

270 Each constraint is explained below. The nonlinearity is the result of constraint (2), where 271 groundwater head is a nonlinear function of pumping rate.

\section{Conditional Head Constraint}

273 To avoid significant decline in groundwater levels, the conditional head constraint (2) is

274 introduced with two non-negative coefficients, $\Delta_{1}$ and $\Delta_{2}$, as policy parameters to control 275 groundwater levels around or above specified target levels at control locations. To handle 276 constraint (2), a unit step function,

$$
\mathrm{H}\left(\mathbf{h}_{t}-\mathbf{h}^{\text {target }}\right)=1, \text { if } \mathbf{h}_{t} \geq \mathbf{h}^{\text {target }} ; 0 \text {, otherwise, }
$$

278 is introduced to make the conditional head constraint more concise:

$$
\mathbf{h}_{t+1}-\mathbf{h}_{t}+\left(\boldsymbol{\Delta}_{1}+\boldsymbol{\Delta}_{2}\right) \mathrm{H}\left(\mathbf{h}_{t}-\mathbf{h}^{\text {target }}\right) \geq \boldsymbol{\Delta}_{1} .
$$


280 This conditional constraint is especially suitable for managing depleting aquifers since it 281 enforces groundwater level increase at least $\Delta_{1}$ units for the next time step if current 282 groundwater level is lower than the specified target level; otherwise, it allows groundwater level 283 to decrease up to $\Delta_{2}$ units for the next time step. $\Delta_{1}$ and $\Delta_{2}$ values are subject to analysts'

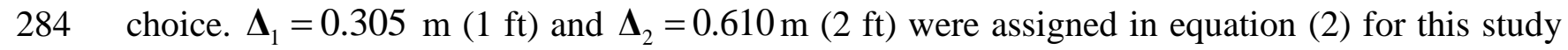
285 since they made target heads at selected observation wells achievable in a 15-year period. 286 Moreover, the coefficient values avoid high groundwater level fluctuations over time.

287 Directly dealing with constraint (9) in the optimization problem is not straightforward. In 288 Appendix A, this study introduces an equivalent set of mixed-integer nonlinear constraints to 289 represent constraint (9). By using the first-order Taylor series expansion to linearize groundwater 290 head with respect to pumping rate, the conditional head constraint (9) is ultimately replaced by a 291 set of mixed-integer linear constraints.

292 Water Balance Equation at Reservoirs

293 Equation (3) is the water balance equation at reservoirs. The term $\sum_{j \in \mathbb{N}} \mathbf{S} \mathbf{p}_{t}^{(j)}$ is the total 294 spill from upstream reservoirs during time period $t$. The USGS gauge record indicates that the 295 initial reservoir storages were full at the beginning of 2011. The VIC hydrologic model, driven 296 by the downscaled temperature and precipitation from 11 ensemble members of future climate 297 change projections, was used to simulate the natural inflow $I_{t}$ entering the reservoirs. The 298 development of future reservoir inflow scenarios is discussed further in the later sections.

299 Water Supply Network

300 Equation (4) is the water balance equation at junction and demand nodes in a water 301 supply network given that reservoirs are the source of surface water and pumping wells are the 
302 source of groundwater to the demand nodes. $\sum_{i \in \text { OUT }} \mathbf{x}_{t}^{(i)}$ is the total outflow and $\sum_{j \in \mathrm{IN}} \mathbf{x}_{t}^{(j)}$ is the total

303 inflow for each node. For a junction node that diverts water to other nodes, $\mathbf{b}_{t}$ is zero. For a

304 demand node, the total inflow is the sum of surface water and groundwater, the total outflow is

305 zero, and $\mathbf{b}_{t}$ is water demand (negative value).

Transformation to Successive MILP

Following Appendix A, a successive MILFP problem is formulated. Further

308 transformation is conducted in Appendix B to transform the successive MILFP problem into a

309 successive mixed-integer linear programming (MILP) problem by the Charnes-Cooper

310 transformation technique (Charnes and Cooper, 1962). This study terminates the successive

311 procedure when the sum of absolute head differences at control locations between iterations is

312 less than a threshold, i.e.,

313

$$
\left\|\mathbf{h}_{t}\left(\mathbf{Q}_{n}^{k+1}\right)-\mathbf{h}_{t}\left(\mathbf{Q}_{n}^{k}\right)\right\|_{1} \leq \eta,
$$

314 where \|\|$_{1}$ is the 1-norm, and $\eta$ is the convergence threshold. For a 15-year network flow

315 optimization, the successive MILFP problem has 4,320 decision variables and 8,190 constraints.

316 After transformation, the successive MILP problem has 4,321 decision variables and 8,551

317 constraints. The IBM ILOG CPLEX Optimizer (IBM, 2009) is used to solve the MILP problem.

\section{$318 \quad$ 2.6. Future Hydroclimate Projections}

319 A hybrid downscaling method (i.e., both dynamical and statistical) is used in this study to

320 develop possible future climate change projections based on the CMIP5 GCM outputs. The

321 coarser resolution GCM outputs $(\sim 150 \mathrm{~km})$ are first dynamically downscaled to $18 \mathrm{~km}$

322 resolution using the International Centre for Theoretical Physics Regional Climate Model

323 version 4 (RegCM4) (Giorgi et al., 2012). The RegCM4-simulated temperature and precipitation 
324 are then statistically interpolated and bias-corrected to $1 / 24^{\circ}(\sim 4 \mathrm{~km})$ resolution for the follow-up

325 hydrologic simulation. This study selects 11 CMIP5 GCMs under the Representative

326 Concentration Pathway (RCP) 8.5 emission scenario (ACCESS1-0, BCC-CSM1-1, CCSM4,

327 CMCC-CM, FGOALS-G2, GFDL-ESM2M, IPSL-CM5A-LR, MIROC5, MPI-ESM-MR, MRI-

328 CGCM3, and Nor-ESM1-M). This hybrid downscaling approach has been described in several

329 recent hydroclimate studies (Ashfaq et al., 2010, 2013).

$330 \quad$ For dynamical downscaling, RegCM4 is forced at its lateral and lower boundaries every 6

331 hours using atmospheric and sea-surface temperature fields from the GCMs. The RegCM4

332 simulations are carried out at $18 \mathrm{~km}$ horizontal grid spacing with 18 vertical levels that cover a

333 domain similar to Diffenbaugh et al. (2011). Each set of experiments consists of 41 years in the

334 baseline (1965-2005) and 41 years in the near future (2010-2050) periods with the first year 335 disregarded for model spin up.

336 While there are over 50 GCMs contributed to CMIP5, only less than one-third archived 337 three-dimensional atmospheric fields at a sub-daily timescale, which is necessary for dynamical 338 downscaling. Therefore, the selection of GCMs in this study is mainly based on data availability.

339 After balancing the resource limitation and the need of multimodel projections, 11 ensemble 340 members — one from each different CMIP5 GCM — are selected in this study. The RCP 8.5 341 scenario is selected because it is closest to the current observed trajectory. The performance and 342 skills of each selected GCM are not specifically evaluated in this study.

343 After RegCM4 simulation, the $18 \mathrm{~km}$ daily precipitation and maximum/minimum surface 344 temperatures are statistically interpolated and bias corrected to ${ }^{1} / 24^{\circ}(\sim 4 \mathrm{~km})$ resolution using a 345 quantile-based bias correction method (Ashfaq et al., 2010, 2013). The $1 / 24^{\circ}(\sim 4 \mathrm{~km})$ resolution 346 1966-2005 monthly precipitation and temperature from the Parameter-elevation Regressions on 
347 Independent Slopes Model (PRISM) (Daly et al., 2008) are used as the historic observation for

348 bias correction. Since most hydrologic models are highly sensitive to minor variations in

349 meteorological forcings, several studies have suggested that statistical bias correction should be

350 performed for the dynamically downscaled precipitation and temperature before conducting

351 hydrologic simulation for better accuracy and lower bias (Rojas et al., 2011; Ahmed et al., 2013).

\section{$352 \quad$ 2.7. Reservoir Inflow Projection by Bayesian model averaging}

353 Driven by the downscaled temperature and precipitation, the VIC model is used to

354 simulate an ensemble of 11 sets of baseline (1966-2005) and future (2011-2050) runoff and

355 streamflow projections. While all dynamically downscaled precipitation and temperature have

356 been bias-corrected by PRISM (i.e., having climatological averages similar to PRISM), the VIC-

357 simulated runoff and streamflow during the baseline period can still vary due to differences in

358 the interannual variability of precipitation and temperature of each ensemble member..

359 Therefore, instead of assigning equal weight to each model, this study adopts the Bayesian model

360 averaging approach to derive an average runoff projection from multiple sets of reservoir inflow

361 projections. Higher weights are assigned to climate models that produce more similar interannual

362 runoff variability to the USGS WaterWatch runoff.

363 Inflows have been considered to follow a lognormal distribution (Vogel and Stedinger,

364 1987; Vogel et al., 1999). In this study, BMA is used to calculate mean reservoir log-inflow 365 projection as follows:

$366 \quad \overline{\mathbf{Y}}_{t}(\mathbf{D})=\sum_{p} \overline{\mathbf{Y}}_{t}\left(\mathbf{D}, \mathbf{M}_{p}\right) \operatorname{Pr}\left(\mathbf{M}_{p} \mid \mathbf{D}\right)$

367 where $\mathbf{Y}_{t}=\ln \left(\mathbf{I}_{t}\right)$ is the vector of natural logarithms of reservoir inflows,

$368 \overline{\mathbf{Y}}_{t}(\mathbf{D})$ is the vector of mean reservoir projected log-inflows at time $t$ given data $\mathbf{D}$, 
$369 \overline{\mathbf{Y}}_{t}\left(\mathbf{D}, \mathbf{M}_{p}\right)$ is the vector of mean reservoir projected log-inflows by hydroclimate model $\mathbf{M}_{p}$, at 370 time $t$ given data $\mathbf{D}$, and

$371 \operatorname{Pr}\left(\mathbf{M}_{p} \mid \mathbf{D}\right)$ is the posterior model probability for the hydroclimate model $\mathbf{M}_{p}$, which is the model 372 weight for the hydroclimate model $\mathrm{M}_{p}$. The variances of the reservoir projected log-inflows are 373 as follows:

374

$$
\sigma^{2}\left(\mathbf{Y}_{t} \mid \mathbf{D}\right)=\sum_{p} \sigma^{2}\left(\mathbf{Y}_{t} \mid \mathbf{D}, \mathbf{M}_{p}\right) \operatorname{Pr}\left(\mathbf{M}_{p} \mid \mathbf{D}\right)+\sum_{p}\left(\overline{\mathbf{Y}}_{t}\left(\mathbf{D}, \mathbf{M}_{p}\right)-\overline{\mathbf{Y}}_{t}(\mathbf{D})\right)^{2} \operatorname{Pr}\left(\mathbf{M}_{p} \mid \mathbf{D}\right)
$$

375 where $\sigma^{2}\left(\mathbf{Y}_{t} \mid \mathbf{D}, \mathbf{M}_{p}\right)$ are the log-inflow variances using the hydroclimate model $\mathbf{M}_{p}$. The internal 376 uncertainty of individual hydroclimate models creates the first term in equation (12). The mean 377 inflow projection uncertainty using different hydroclimate models creates the second term in 378 equation (12).

379 Calculating $\overline{\mathbf{Y}}_{t}\left(\mathbf{D}, \mathbf{M}_{p}\right)$ can be challenging if full model parameter range of hydroclimate 380 model $\mathbf{M}_{p}$ is taken into account. Following the suggestion of Draper (1995), $\overline{\mathbf{Y}}_{t}\left(\mathbf{D}, \mathbf{M}_{p}\right)$ is 381 approximated by $\mathbf{Y}_{t}\left(\mathbf{D}, \hat{\boldsymbol{\beta}}_{p}, \mathbf{M}_{p}\right)$, where $\hat{\boldsymbol{\beta}}_{p}$ is the maximum likelihood estimate of model 382 parameters $\hat{\boldsymbol{\beta}}_{p}$ of the hydroclimate model $\mathbf{M}_{p}$. Therefore, $\overline{\mathbf{Y}}_{t}\left(\mathbf{D}, \mathbf{M}_{p}\right)$ is approximated by the log383 runoff output of the calibrated VIC model with climate forcing from a GCM. Calculating the model weight $\operatorname{Pr}\left(\mathrm{M}_{p} \mid \mathbf{D}\right)$ is another challenging task due to the 385 calculation of the marginal likelihood in the Bayes' theorem. Many studies have contributed to 386 the discussions of how $\operatorname{Pr}\left(\mathrm{M}_{p} \mid \mathbf{D}\right)$ be calculated. This study does not elaborate on these 387 discussions, but simply adopts the Bayesian information criterion (Schwarz, 1978) and the 388 variance window (Tsai and $\mathrm{Li}, 2008$ ) to approximate the marginal likelihood function. The 389 Bayesian information criterion (BIC) is 


$$
\mathrm{BIC}_{p}=\sum_{i} \frac{\left(\ln \mathrm{Q}_{p, i}-\ln \mathrm{Q}_{i}^{\text {obs }}\right)^{2}}{\sigma_{p, i}^{2}}+N \ln 2 \pi+k_{p} \ln (N),
$$

391 where

$392 \ln \mathrm{Q}_{p, i}$ is the $\mathrm{i}^{\text {th }} \log$-runoff projected by the hydroclimate model $\mathrm{M}_{p}$,

$393 \ln \mathrm{Q}_{i}^{o b s}$ is the $\mathrm{i}^{\text {th }}$ USGS WaterWatch runoff data,

$394 \sigma_{p, i}^{2}$ is the error variance for the $\mathrm{i}^{\text {th }}$ runoff data,

$395 N$ is the number runoff data, and

$396 k_{p}$ is the number of unknown model parameters. The model weight can be approximated by the

397 following equation:

398

$$
\operatorname{Pr}\left(\mathrm{M}_{p} \mid \mathbf{D}\right) \approx \frac{\exp \left(-\frac{1}{2} \alpha\left(\mathrm{BIC}_{p}-\mathrm{BIC}_{\min }\right)\right)}{\sum_{q} \exp \left(-\frac{1}{2} \alpha\left(\mathrm{BIC}_{q}-\mathrm{BIC}_{\min }\right)\right)},
$$

399 where $\alpha$ is the scaling factor, and $\mathrm{BIC}_{\min }$ is the minimum $\mathrm{BIC}$ value of all hydroclimate models.

400 Tsai and $\mathrm{Li}$ (2008) provide the details on implementation. Climate models that produce

401 interannual runoff variability similar to the USGS WaterWatch log-runoffs will have smaller

402 BIC values and higher model weights.

\section{3. Results and Discussion}

\section{3.1. Comparison with Other CMIP5 Models}

Since the adopted hydroclimate ensemble was restricted to $11 \mathrm{GCMs}$, their relative 406 change compared to other CMIP5 members was evaluated (Fig. 4). RegCM-RCP8.5 represents

407 the 11 downscaled models used in this study. A total of 97 statistically downscaled climate 408 projections under four emission scenarios (RCPs 2.6, 4.5, 6.0, and 8.5) are obtained from the bias 409 correction spatial disaggregation (BCSD) data archive (Brekke et al., 2013). The average annual 
410 percentage change of precipitation and the degree change of temperature from the 1966-2005

411 baseline to the 2011-2050 near future period in the study area are calculated. The ensemble

412 median of the 97 BCSD downscaled projections is marked by a dashed line (Fig. 4). All models

413 project a consistent increase in temperature ranging from $+0.5^{\circ} \mathrm{C}$ to $\sim+2.5^{\circ} \mathrm{C}$, and $-15 \%$ to $+20 \%$

414 change in precipitation is projected with relatively large intermodel variability. In terms of the

415 multimodel median, the 11 climate projections used in this study are around $-0.5^{\circ} \mathrm{C}$ cooler and

$416+5 \%$ wetter than the BCSD in the study area. Although the highest emission scenario is chosen,

417 the 11 simulations are not biased toward the warming side. This is because the difference among

418 various emission scenarios only becomes significant after 2030 (Peters et al., 2013), so climate

419 variability remains the main governing factor in the near-term $21^{\text {st }}$ century projection period.

[Figure 4]

\section{$421 \quad$ 3.2. Runoff Projections under Climate Change Scenarios}

422 Changes in near future seasonal runoffs (2011-2049) projected by different hydroclimate

423 ensemble members with respect to the historical seasonal WaterWatch runoffs (1980-2005) for

424 Bayou D'Arbonne subbasin were shown in Table 2. These changes indicate a decrease in near

425 future runoff in winter (DJF). This is consistent with other studies (Seager et al., 2013; Milly et

426 al., 2005; Mulholland et al., 1997) that projected an overall decrease in mean runoff for the

427 southern region of the US; however, the decrease would be greater than $10 \%$ in this region. On

428 the other hand, near future runoff would increase in summer (JJA) and fall (SON) significantly.

429 Near future runoff is likely to increase in spring (MAM). Although not shown here, similar near

430 future runoff changes were also obtained for Loggy Bayou subbasin. The near future mean

431 annual runoffs due to different GCMs could decrease by $180.74 \mathrm{~mm}$, or they could increase by

$43290.75 \mathrm{~mm}$ in Loggy Bayou subbasin as compared to the historical mean annual runoffs, and there 
433 could be a $164.58 \mathrm{~mm}$ decrease and $133.11 \mathrm{~mm}$ increase in Bayou D'Arbonne subbasin. The

434 hydroclimate modeling results show considerable spread of possible future outcomes.

[Table 2]

The model weights for the hydroclimate ensembles were obtained based on their similar

437 interannual variability to the USGS WaterWatch log-runoffs for the subbasins during 1980-2005

438 (14). The probability plot shown in Fig. 5 indicates that the monthly runoffs can be reasonably

439 assumed to be log normally distributed. As shown in Table 3, RegCM4-CCSM4 has the highest

440 similarity to WaterWatch log-runoffs, and RegCM4-MPI-ESM-MR has the least similarity.

441 BMA means of log-runoffs were obtained by using equation (11), and log runoffs were obtained

442 by using equation (12) to determine $95 \%$ confidence interval. After back-transformation, most of

443 the USGS WaterWatch runoffs are within the 95\% confidence interval as shown Figs. $6 \mathrm{a}$ and $6 \mathrm{~b}$

444 for the historical period.

The BMA means and the $95 \%$ confidence interval of near future runoffs are shown in

449 Figs. 6c and 6d. The results indicate high runoff projection uncertainty in years 2017, 2019, 2023

450 and 2024. By comparing with the average annual runoff of the historical period, the BMA results

451 indicate an increase of $66.95 \mathrm{~mm} /$ year for Bayou D’Arbonne subbasin and an increase of 61.89

$452 \mathrm{~mm} /$ year for Loggy Bayou subbasin in the near future period. This is contrary to the previous

453 findings (Seager et al., 2013; Milly et al., 2005; Mulholland et al., 1997) that projected runoff

454 decrease in the US southern region.

\section{3.3. Inflow Projections under Climate Change Scenarios}


Future monthly inflows to Lake Bistineau were estimated the same as the runoffs for

457 Loggy Bayou subbasin (Fig. 6c). Future monthly inflows to Bayou D’Arbonne Lake, Lake

458 Claiborne, and Corney Lake were calculated from the fractional runoffs of Bayou D'Arbonne

459 subbasin (see Fig. 6d) based on the ratios of their drainage areas to those in the Bayou

460 D'Arbonne subbasin area. The watershed areas shown in Fig. 1a are 4,157 $\mathrm{km}^{2}$ for Bayou

461 D'Arbonne Lake, $334 \mathrm{~km}^{2}$ for Lake Claiborne, 1,109 km2 for Corney Lake, and 3,768 $\mathrm{km}^{2}$ for

462 Lake Bistineau. Based on the BMA means and variances of log-runoffs under the Gaussian

463 assumption, this study investigates the optimized conjunctive management solutions under the

464 future low inflow projections at 50\%, 10\%, and $2.5 \%$ cumulative probability level as shown in $465 \quad$ Fig. 7.

[Figure 7]

\section{3.4. Impact of Conjunctive Use on Reservoirs}

Noticeable deficits in the reservoir storages would be produced at the $2.5 \%$ low inflow, as

469 shown in Fig. 8. The storage capacity of Corney Lake is relatively very small and is not shown

470 here. Over the 15-year span (2011-2025), Corney Lake would lose 18 million $\mathrm{m}^{3}$ (4,612 MG) in

471 storage, Bayou D'Arbonne Lake would lose 4,547 million $\mathrm{m}^{3}$ (1,201,123 MG), Lake Claiborne

472 would lose 899 million $\mathrm{m}^{3}$ (237,557 MG), and Lake Bistineau would lose 1,954 million $\mathrm{m}^{3}$

473 (516,071 MG). Storage would decrease significantly at Lakes Claiborne and Bistineau starting in

474 the summer of 2023 because the $2.5 \%$ low inflow would not be able to meet demands without

475 significantly using storages. Storage loss would not be noticeable at the $10 \%$ and $50 \%$ 476 cumulative low inflow probability levels. 
Low inflows would result in low spills from the reservoirs, as shown in Fig. 9. For the

$4792.5 \%$ low inflow, Bayou D’Arbonne Lake would spill only $0.94 \%$ of its annual inflows on 480 average to Ouachita River. Lake Bistineau would spill only $2.55 \%$ of its annual inflows on 481 average to Red River. These low spills might not be favorable to environmental flows in some 482 months during 2011 to 2025. However, the 50\% low inflows would allow Bayou D'Arbonne 483 Lake to spill $60.29 \%$ of its annual inflows on average to the Ouachita River. Lake Bistineau 484 would spill $56.7 \%$ of its annual inflows on average to Red River. These high spills would satisfy 485 environmental flows.

\section{3.5. Impact of Conjunctive Use on Sparta Aquifer}

Due to sufficient surface water (inflows plus reservoir storages) to meet water demand in 2011-2025, the same optimized groundwater pumping rates resulted, regardless of considering $2.5 \%, 10 \%$, or $50 \%$ low inflow (Fig. 10). The annual mean of future optimized pumpage for

491 pumping center Ou-W1 would decrease by $45.55 \%$, and at Ou-W2 it would decrease by $99.22 \%$

492 as compared to decreases in 2001-2010. However, the annual mean of future optimized 493 pumpage for pumping center Ou-W3 would increase by $18.62 \%$, and Ou-W4 it would increase 494 by $20.55 \%$. Overall, conjunctive management shows that the annual mean pumpage in Ouachita 495 would decrease from 2,4491,614 m³/day (6,470 MGD from 2001 to 2010) to $18,029,916 \mathrm{~m}^{3} /$ day 496 (4,763 MGD from 2011 to 2025), a 26.38\% reduction. This could be offset by the surface water. 497 The annual mean of optimized pumpage at L-W1 in Lincoln would decrease by $19.41 \%$ as 498 compared to the decreases in 2001-2010. The annual mean of optimized pumpage at U-W1 in 499 Union would increase by $195.77 \%$. 
Using $\Delta_{1}=0.305 \mathrm{~m}(1 \mathrm{ft})$ and $\Delta_{2}=0.610 \mathrm{~m}$ (2ft) in equation (2), as shown in Fig. 11,

502 groundwater levels at the selected control points would reach or pass their target levels by 2025.

503 By significantly reducing pumpage in Ouachita, groundwater level at U-26 would still increase

504 even though the pumping rate increases for U-W1. In summary, the target groundwater levels

505 could be achieved by only decreasing 13,703 $\mathrm{m}^{3} /$ day (3.62 MGD) from the annual mean

506 pumpage during 2001-2010. This pumpage reduction is significantly lower than the 68,137

$507 \mathrm{~m}^{3} /$ day (18 MGD) reduction from the Sparta aquifer recommended by Meyer et al. (2002).

[Figure 11]

\section{3.6. Optimized Surface Water Allocations}

The optimized annual groundwater and monthly surface water allocations for Monroe

511 and Farmerville are shown in Fig. 12. Monroe would be a significant user of Bayou D'Arbonne

512 Lake, which would use an average of 132,489 $\mathrm{m}^{3} /$ day (35 MGD) during 2011-2025. About 18\%

513 of water demand for Farmerville would come from Bayou D’Arbonne Lake after 2012. Homer

514 would be constantly supplied by Lake Claiborne. The conjunctive-use model suggests that

515 Minden would be constantly supplied by Lake Bistineau, although it might receive surface water

516 from Lake Claiborne. The majority of surface water to Ruston would be shifted from Bayou

517 D'Arbonne Lake to Lake Bistineau, as shown in Figs. 13a-13c as inflows decreases. The

518 majority of surface water for Arcadia would come from Lake Bistineau, as shown in Figs. 13d

519 and 13f. As inflows decrease, Arcadia would receive less water from Lake Claiborne. For the

$520 \quad 2.5 \%$ low inflow case, Lake Bistineau would supply $100 \%$ of the water to Arcadia. 
The result indicates that Lake Bistineau would be a reliable surface water supply source

524 to Ruston and Arcadia. At the $2.5 \%$ low inflow, Bayou D'Arbonne Lake would not be able to

525 contribute major surface water to Ruston because it would need to fulfill the water demand for

526 Monroe and Farmerville first. Similarly, Lake Claiborne would not be able to supply surface

527 water to Arcadia, as it would need to fulfill the water demand for Homer first.

\section{4. Conclusion}

The MILFP provides a simple, computationally efficient approach to optimize conflicting

530 objectives. For a conjunctive use, the successive MILFP is suitable for optimizing groundwater

531 and surface water uses by integrating a groundwater model and a multi-reservoir water supply

532 network model through the response matrix approach. This study expands the Charnes-Cooper

533 transformation technique to include integer variables so that the optimal solution for the

534 successive MILFP problem can be efficiently obtained by solving a successive MILP problem.

535 The proposed conjunctive-use model for the case study successfully demonstrates this technique.

536 Future inflow estimates to the reservoirs rely on future runoff projections, which present

537 the key uncertainty to the conjunctive management. Through the BMA analysis on an ensemble

538 of 11 sets of downscaled hydroclimate projections, this study found that the near future runoff

539 (2011-2049) for northern Louisiana would be likely to decrease in winter, but it would be likely

540 to increase in spring, summer and fall. Overall, northern Louisiana would likely be in a wetter

541 condition in the near future.

542 Due to the projected wetter condition, the conjunctive-use modeling result indicates that

543 water demands in northern Louisiana for the future period (2011-2025) would be satisfied even

544 with a $2.5 \%$ low inflow projection and a rising groundwater level in the Sparta aquifer. Future

545 surface water would counterbalance the groundwater pumping reduction. It was found that a 
546 significant reduction in groundwater withdrawal in Ouachita would elevate the overall

547 groundwater level for northern Louisiana. The conjunctive-use model showed that the target

548 groundwater levels would be met by 2025 by reducing annual groundwater pumpage by 13,703

$549 \mathrm{~m}^{3} /$ day (3.62 MGD).

550 Through the conjunctive-use model, it was determined that Lake Bistineau would be a

551 reliable future surface water source to Ruston and Arcadia given the proposed network

552 configuration. For the $2.5 \%$ low inflow projection, Bayou D’Arbonne Lake would not be able to

553 provide a large amount of surface water to Ruston, as it would have to first satisfy Farmerville

554 and Monroe demands. Similarly, Lake Claiborne would not be able to provide a noticeable

555 amount of surface to Arcadia at a very low projected inflow because it would have to satisfy

556 Homer demands first.

\section{Acknowledgements}

559 This work was supported in part by the Louisiana Board of Regents under award number 560 LEQSF(2012-15)-RD-A-03 and by the U.S. Geological Survey under Grant/Cooperative 561 Agreement No. G11AP20082 (through LWRRI). The authors acknowledge Brian Clark of 562 USGS for providing the Sparta groundwater model, Pierre Sargent of USGS for providing water 563 use data for northern Louisiana, and the Louisiana Sparta Ground Water Commission for 564 providing technical reports. The LSU Center for Computation \& Technology (CCT) and the 565 High Performance Computing (HPC) are acknowledged for providing computing resources and 566 technical assistance. This paper was coauthored by employees of the Oak Ridge National 567 Laboratory, managed by UT Battelle, LLC, under contract DE-AC05-00OR22725 with the U.S. 568 Department of Energy. Accordingly, the publisher, by accepting the article for publication, 
569 acknowledges that the United States government retains a nonexclusive, paid-up, irrevocable,

570 worldwide license to publish or reproduce the published form of this manuscript, or allow others

571 to do so, for United States government purposes.

572

573 Appendix A: Conditional Head Constraint Linearization

574 This study introduces an equivalent set of inequality constraints (A1)-(A3) to represent

575 the conditional head constraint (9) as follows:

576

577

578

$$
\mathbf{h}_{t+1}-\mathbf{h}_{t}-\operatorname{diag}\left(\boldsymbol{\Delta}_{1}+\boldsymbol{\Delta}_{2}\right) \mathbf{u}_{t} \geq-\boldsymbol{\Delta}_{2}
$$

$$
\mathbf{h}_{t}+\operatorname{diag}\left(\mathbf{h}^{\text {target }}-\mathbf{L}_{h}\right) \mathbf{u}_{t} \geq \mathbf{h}^{\text {target }} \text {, and }
$$

$$
\mathbf{h}_{t}+\operatorname{diag}\left(\mathbf{U}_{h}-\mathbf{h}^{\text {target }}\right) \mathbf{u}_{t}<\mathbf{U}_{h},
$$

579 where $\mathbf{u}_{t}$ is the vector of binary variables at time $t, \mathbf{L}_{h}$ is the vector of the lower bound for

580 groundwater head at control locations, and $\mathbf{U}_{h}$ is the vector of the upper bound for groundwater

581 head at control locations. $\operatorname{diag}(\square)$ makes a vector become a diagonal matrix. $\mathbf{u}_{t}=\mathbf{0}$ indicates 582 $\mathbf{h}_{t} \geq \mathbf{h}^{\text {target }}$ and $\mathbf{u}_{t}=\mathbf{1}$ indicates $\mathbf{h}_{t}<\mathbf{h}^{\text {target }}$. Using the first-order Taylor series expansion (Peralta et al., 1991; Theodossiou, 2004),

584 groundwater head, $\mathbf{h}_{t}$, is linearized with respect to pumping rate $\mathbf{Q}_{n}$ as follows:

$$
\mathbf{h}_{t}^{k+1} \approx \mathbf{h}_{t}^{k}+\mathbf{J}_{t}^{k}\left(\mathbf{Q}_{n}^{k+1}-\mathbf{Q}_{n}^{k}\right)
$$

586 where $\mathbf{J}_{t}^{k}=\partial \mathbf{h}_{t} /\left.\partial \mathbf{Q}\right|_{\mathbf{Q}=\mathbf{Q}_{n}^{k}}$ is the Jacobian matrix, $\mathbf{Q}_{n}^{k}$ is the vector of pumping rate at the $\mathrm{k}^{\text {th }}$ 587 iteration, and $\mathbf{h}_{t}^{k}=\mathbf{h}_{t}\left(\mathbf{Q}_{n}^{k}\right)$. Substituting equation (A4) into constraints (A1)-(A3), linear 588 constraints at the $\mathrm{k}^{\text {th }}$ iteration are obtained: 


$$
\left(\mathbf{J}_{t+1}^{k}-\mathbf{J}_{t}^{k}\right) \mathbf{Q}_{n}^{k+1}-\operatorname{diag}\left(\boldsymbol{\Delta}_{1}+\boldsymbol{\Delta}_{2}\right) \mathbf{u}_{t} \geq-\boldsymbol{\Delta}_{2}-\left(\mathbf{h}_{t+1}^{k}-\mathbf{h}_{t}^{k}\right)+\left(\mathbf{J}_{t+1}^{k}-\mathbf{J}_{t}^{k}\right) \mathbf{Q}_{n}^{k}
$$

$$
\mathbf{J}_{t}^{k} \mathbf{Q}_{n}^{k+1}+\operatorname{diag}\left(\mathbf{h}^{\text {target }}-\mathbf{L}_{h}\right) \mathbf{u}_{t} \geq \mathbf{h}^{\text {target }}-\mathbf{h}_{t}^{k}+\mathbf{J}_{t}^{k} \mathbf{Q}_{n}^{k}, \text { and }
$$

$$
\mathbf{J}_{t}^{k} \mathbf{Q}_{n}^{k+1}+\operatorname{diag}\left(\mathbf{U}_{h}-\mathbf{h}^{\text {target }}\right) \mathbf{u}_{t} \leq \mathbf{U}_{h}-\mathbf{h}_{t}^{k}+\mathbf{J}_{t}^{k} \mathbf{Q}_{n}^{k}
$$

592 where $\mathbf{J}_{t+1}^{k}, \mathbf{J}_{t}^{k}$, and $\mathbf{Q}_{n}^{k}$ are known values from the previous iteration, $k$, and $\mathbf{Q}_{n}^{k+1}$ are the 593 decision variables (unknown) to be determined at the current iteration, $k+1$. A procedure is 594 needed to successively improve the solution until a stopping criterion is met.

\section{Appendix B: Transformation of MILFP to MILP}

Following the details provided in Appendix A, the fractional programming problem can

599 follows:

600

$$
\operatorname{Maximize} \frac{\sum_{n} \mathbf{1}^{T} \mathbf{Q}_{n}^{k+1}}{\sum_{t} \mathbf{1}^{T}\left(\mathbf{S}_{\max }-\mathbf{S}_{t}\right)+\beta},
$$

subject to

$$
\left(\mathbf{J}_{t+1}^{k}-\mathbf{J}_{t}^{k}\right) \mathbf{Q}_{n}^{k+1}-\operatorname{diag}\left(\boldsymbol{\Delta}_{1}+\boldsymbol{\Delta}_{2}\right) \mathbf{u}_{t} \geq-\boldsymbol{\Delta}_{2}-\left(\mathbf{h}_{t+1}^{k}-\mathbf{h}_{t}^{k}\right)+\left(\mathbf{J}_{t+1}^{k}-\mathbf{J}_{t}^{k}\right) \mathbf{Q}_{n}^{k},
$$




$$
\psi=\frac{1}{\sum_{t} \mathbf{1}^{T}\left(\mathbf{S}_{\max }-\mathbf{S}_{t}\right)+\beta},
$$

609

610

611

612

613 original MIFLP problem is transformed to the following mixed-integer nonlinear programming

614 problem (MINLP):

615

$$
\text { Maximize } \sum_{n} \mathbf{1}^{T} \overline{\mathbf{Q}}_{n}^{k+1},
$$

subject to

$$
\begin{aligned}
& \left(\mathbf{J}_{t+1}^{k}-\mathbf{J}_{t}^{k}\right) \overline{\mathbf{Q}}_{n}^{k+1}-\operatorname{diag}\left(\boldsymbol{\Delta}_{1}+\boldsymbol{\Delta}_{2}\right) \overline{\mathbf{u}}_{t}+\left[\boldsymbol{\Delta}_{2}+\left(\mathbf{h}_{t+1}^{k}-\mathbf{h}_{t}^{k}\right)-\left(\mathbf{J}_{t+1}^{k}-\mathbf{J}_{t}^{k}\right) \mathbf{Q}_{n}^{k}\right] \psi \geq 0, \\
& \mathbf{J}_{t}^{k} \overline{\mathbf{Q}}_{n}^{k+1}+\operatorname{diag}\left(\mathbf{h}^{\text {target }}-\mathbf{L}_{h}\right) \overline{\mathbf{u}}_{t}-\left[\mathbf{h}^{\text {target }}-\mathbf{h}_{t}^{k}+\mathbf{J}_{t}^{k} \mathbf{Q}_{n}^{k}\right] \psi \geq 0, \\
& \mathbf{J}_{t}^{k} \overline{\mathbf{Q}}_{n}^{k+1}+\operatorname{diag}\left(\mathbf{U}_{h}-\mathbf{h}^{\text {target }}\right) \overline{\mathbf{u}}_{t}-\left[\mathbf{U}_{h}-\mathbf{h}_{t}^{k}+\mathbf{J}_{t}^{k} \mathbf{Q}_{n}^{k}\right] \psi \leq 0, \\
& \overline{\mathbf{S}}_{t+1}=\overline{\mathbf{S}}_{t}+\mathbf{I}_{t} \psi+\sum_{j \in \mathbb{N}} \overline{\mathbf{S}}_{t}^{(j)}-\overline{\mathbf{R}}_{t}-\overline{\mathbf{S p}}_{t}-\mathbf{E}_{t} \psi, \text { and } \\
& \sum_{i \in \text { OUT }} \overline{\mathbf{x}}_{t}^{(i)}-\sum_{j \in \mathbb{N}} \overline{\mathbf{x}}_{t}^{(j)}=\mathbf{b}_{t} \psi .
\end{aligned}
$$


626 The discontinuous variables product term $\overline{\mathbf{u}}_{t}$ in the constraints (B11)-(B13) imposes additional

627 nonlinearity. To address with the discontinuous variables, the following constraints are added:

628

629

630

631

$$
\overline{\mathbf{u}}_{t}-U \mathbf{u}_{t} \leq \mathbf{0}
$$

632 so that $\overline{\mathbf{u}}_{t}$ can be treated as continuous variables. $L$ is a negative value, and $U$ is an upper bound

633 of $\psi$. By adding the constraints (B18)-(B21), the successive MINLP problem becomes a

634 successive mixed-integer linear programming (MILP) problem.

635

636

\section{References}

637 Ajami, N. K., Duan, Q., Gao, X., and Sorooshian, S., 2006. Multimodel combination techniques for analysis of hydrological simulations: Application to distributed model

Ashfaq, M., L. Bowling C., Cherkauer K., Pal J. S., and Diffenbaugh N. S., 2010. Influence of US. Journal of Geophysical Research: Atmospheres, 118(19), 10676-10693. 
648 Bastola, S., Murphy, C., and Sweeney, J., 2011. The role of hydrological modelling uncertainties 649 in climate change impact assessments of Irish river catchments. Advances in Water $650 \quad$ Resources, 34(5), 562-576. doi:10.1016/j.advwatres.2011.01.008.

651 Bazargan-Lari, M., Kerachian, R., and Mansoori, A., 2009. A conflict-resolution model for the 652

Bhattacharjya, R. K., and Datta, B., 2005. Optimal management of coastal aquifers using linked simulation optimization approach. Water Resources Management, 19(3), 295-320. doi:10.1007/s11269-005-3180-9.

Bosshard, T., Carambia, M., Goergen, K., Kotlarski, S., Krahe, P., Zappa, M., and Schär, C., 2013. Quantifying uncertainty sources in an ensemble of hydrological climate-impact projections. Water Resources Research, 49(3), 1523-1536. doi:10.1029/2011WR011533.

Brakebill, J. W., Wolock, D. M., and Terziotti, S. E., 2011. Digital hydrologic networks supporting applications related to spatially referenced regression modeling. Journal of the American Water Resources Association, 47(5), 916-932. doi:10.1111/j.17521688.2011.00578.x.

Brekke, L., Wood, A., and Pruitt, T., 2013. Downscaled CMIP3 and CMIP5 Hydrology Projections: Release of Hydrology Projections, Comparison with Preceding Information, and Summary of User Needs, U.S. Department of the Interior, Bureau of Reclamation, Technical Services Center, Denver, CO. 
Buser, C. M., Künsch, H. R., Lüthi, D., Wild, M., and Schär, C., 2009. Bayesian multi-model projection of climate: Bias assumptions and interannual variability. Climate Dynamics, 33(6), 849-868. doi:10.1007/s00382-009-0588-6.

672 Charnes, A., and Cooper, W. W., 1962. Programming with linear fractional functionals. Naval Research Logistics Quarterly, 9(3-4), 181-186. doi:10.1002/nav.3800090303.

674 Christensen, N. S., Wood, A. W. Voisin, N., Lettenmaier, D. P., and Palmer, R. N., 2004. The effects of climate change on the hydrology and water resources of the Colorado River basin. Climatic Change, 62(1-3), 337-363. doi:10.1023/B:CLIM.0000013684.13621.1f.

Daly, C., Halbleib, M., Smith, J. I., Gibson, W. P., Doggett, M. K., Taylor, G. H., Curtis, J., and Pasteris, P. P., 2008. Physiographically sensitive mapping of climatological temperature and precipitation across the conterminous United States, International Journal of Climatology, 28(15), 2031-2064. doi:10.1002/joc.1688.

Diffenbaugh, N. S., Ashfaq, M., and Scherer, M., 2011. Transient regional climate change: analysis of the summer climate response in a high-resolution, century-scale, ensemble experiment over the continental United States. Journal of Geophysical Research, 116(D24). doi:10.1029/2011JD016458.

Dong, L., Xiong, L., and Yu, K., 2013. Uncertainty analysis of multiple hydrologic models using the Bayesian model averaging method. Journal of Applied Mathematics, 2013, 1-11. doi:10.1155/2013/346045.

Draper, D., 1995. Inference and hierarchical modeling in the social sciences. Journal of Educational and Behavioral Statistics, 20(2), 115-147. 
Duan, Q., Ajami, N. K., Gao, X., and Sorooshian, S., 2007. Multi-model ensemble hydrologic prediction using Bayesian model averaging. Advances in Water Resources, 30(5), 13711386. doi:10.1016/j.advwatres.2006.11.014.

USEPA and USGS, 2010. NHDPlus user guide, U.S. Environmental Protection Agency and U.S. Geological Survey, available at: ftp://ftp.horizonsystems.com/NHDPlus/NHDPlusV1/documentation/NHDPLUSV1_UserGuide.pdf, accessed March 2016.

Fasakhodi, A., Nouri, S., and Amini, M., 2010. Water resources sustainability and optimal cropping pattern in farming systems: A multi-objective fractional goal programming approach. Water Resources Management, 24(15): 4639-4657. doi:10.1007/s11269-0109683-z.

Gesch, D., Oimoen, M., Greenlee, S., Nelson, C., Steuck, M., and Tyler, D., 2002. The national elevation dataset, Photogramm. Eng. Remote Sens., 68(1), 5-11.

Giorgi, F., Coppola, E., Solmon, F., Mariotti, L., Sylla, M. B., Bi, X., Elguindi, N. , Diro, G. T., Nair1, V., Giuliani, G., Turuncoglu, U. U., Cozzini, S., Güttler, I., O’Brien, T. A., Tawfik, A. B., Shalaby, A., Zakey, A. S., Steiner, A. L., Stordal, F., Sloan, L. C., Turuncoglu, U. U., 2012. RegCM4: Model description and preliminary tests over multiple CORDEX domains. Climate Research, 2(7), 7-29. doi:10.3354/cr01018.

Guo, P., Chen, X., Li, M., and Li, J., 2014. Fuzzy chance-constrained linear fractional programming approach for optimal water allocation. Stochastic Environmental Research and Risk Assessment, 28(6), 1601-1612. doi:10.1007/s00477-013-0810-2.

Hagemann, S., Chen, C., Clark, D. Folwell, S. Gosling, S. N., Haddeland, I., Hannasaki, N., Heinke, J., Ludwig, F., Voss, F., and Wiltshire, A. J., 2013. Climate change impact on 
available water resources obtained using multiple global climate and hydrology models. Earth System Dynamics, 4, 129-144. doi:10.5194/esd-4-129-2013.

715 Hoeting, J. A., Madigan, D., Raftery, A. E., and Volinsky, C. T., 1999. Bayesian model

716 averaging: A tutorial. Statistical Science, 382-401.

717 IBM, 2009. IBM ILOG CPLEX Computer Program, version 12.1, Armonk, NY: International 718 Business Machines Corporation.

719 Katsifarakis, K. L., and Petala, Z., 2006. Combining genetic algorithms and boundary elements to optimize coastal aquifers' management. Journal of Hydrology, 327(1-2), 200-207.

722 LaDNR, 2015. Areas of Ground Water Concerns. Office of Conservation, Louisiana Department of Natural Resources. Available on the World Wide Web, accessed May 7, 2015, at URL http://dnr.louisiana.gov/index.cfm?md=pagebuilder\&tmp=home\&pid=473

Lara, P. and Stancu-Minasian, I., 1999. Fractional programming: a tool for the assessment of sustainability. Agricultural Systems, 62(2): 131-141. doi:10.1016/S0308$521 X(99) 00062-1$.

Liang, X., Lettenmaier, D. P., Wood, E. F., and Burges, S. J., 1994. A simple hydrologically based model of land surface water and energy fluxes for general circulation models.

732 Liang, X., Wood, E. F., and Lettenmaier, D. P., 1996. Surface soil moisture parameterization of 733 the VIC-2L model: Evaluation and modification, Global and Planetary Change, 13(1), 734 195-206. doi:10.1016/0921-8181(95)00046-1. 
Liang, Z., Wang, D., Guo, Y., Zhang, Y., and Dai, R., 2013. Application of bayesian model averaging approach to multimodel ensemble hydrologic forecasting. Journal of Hydrologic Engineering, 18(11), 1426-1436. doi:10.1061/(ASCE)HE.19435584.0000493.

Lohmann, D., Raschke, E., Nijssen, B. and Lettenmaier, D. P., 1998. Regional scale hydrology, Part 1: Formulation of the VIC-2L model coupled to a routing model. Hydrological Sciences Journal, 43, 131-141. doi:10.1080/02626669809492107.

Mahoney, K., Alexander, M. A., Thompson, G., Barsugli, J. J., and Scott, J. D., 2012. Changes in hail and flood risk in high-resolution simulations over Colorado's mountains. Nature Climate Change, 2(2), 125-131. doi:10.1038/nclimate1344.

Mantoglou, A., 2003. Pumping management of coastal aquifers using analytical models of saltwater intrusion. Water Resources Research, 39(12), 1335. doi:10.1029/2002WR001891.

McKee, P. W., and Clark, B. R., 2003. Development and calibration of a groundwater flow model for the Sparta aquifer of Southeastern Arkansas and North-Central Louisiana and simulated response to withdrawals, 1998-2027. USGS Water-Resources Investigations Report 03-4132.

Milly, P. C., Dunne, K. A., and Vecchia, A. V., 2005. Global pattern of trends in streamflow and water availability in a changing climate. Nature, 438(7066), 347-350. doi:10.1038/nature04312.

Min, S. K., Simonis, D., and Hense, A., 2007. Probabilistic climate change predictions applying Bayesian model averaging. Philosophical Transactions of the Royal Society of London 
A: Mathematical, Physical and Engineering Sciences, 365(1857), 2103-2116. doi:10.1098/rsta.2007.2070.

Meyer, Meyer, LeCroix, Hixson, Inc., Lazenby and Associates, Louisiana Tech University, URS Corporation, Charles W. Smoot and Frye-Magee., 2002. Sparta groundwater study: A study commissioned by the Sparta Groundwater Conservation District Commission, Louisiana.

Mohammad Rezapour Tabari, M., and Yazdi, A., 2014. Conjunctive Use of Surface and Groundwater with Inter-Basin Transfer Approach: Case Study Piranshahr. Water Resources Management, Springer, 28(8), 1887-1906. doi:10.1007/s11269-014-0578-2.

Mulholland, P. J., Best, G. R., Coutant, C. C., Hornberger, G. M., Meyer, J. L., Robinson, P. J., Stenberg, J. R., Turner, R. E., Vera-Herrera, F., and Wetzel, R. G., 1997. Effects of climate change on freshwater ecosystems of the south-eastern United States and the Gulf Coast of Mexico. Hydrological Processes, 11(8), 949-970. doi:10.1002/(SICI)10991085(19970630)11:8<949::AID-HYP513>3.0.CO;2-G.

Najafi, M. R., Moradkhani, H., and Jung, I. W., 2011. Assessing the uncertainties of hydrologic model selection in climate change impact studies. Hydrological Processes, 25(18), 28142826. doi:10.1002/hyp.8043.

Oubeidillah, A. A., Kao, S. C., Ashfaq, M., Naz, B. S., and Tootle, G., 2014. A large-scale, highresolution hydrological model parameter data set for climate change impact assessment for the conterminous US. Hydrology and Earth System Sciences, 18(1), 67-84. doi:10.5194/hess-18-67-2014. 
778 Peralta, R. C., Azarmnia, H., and Takahashi, S., 1991. Embedding and response matrix techniques for maximizing steady-state ground-water extraction: Computational comparison. Ground Water, 29(3), 357-364. doi:10.1111/j.1745-6584.1991.tb00526.x.

781 Peters, G. P., Andrew, R. M., Boden, T., Canadell, J. G., Ciais, P., Le Quéré, C., Marland, G.,

Raftery, A. E., and Zheng, Y., 2003. Long-run performance of Bayesian model averaging. Raupach, M. R., and Wilson, C., 2013. The challenge to keep global warming below 2 Journal of the American Statistical Association, 98(464), 931-938. doi:10.1198/016214503000000891.

Ramesh, H., and Mahesha, A., 2008. Simulation of varada aquifer system for sustainable groundwater development. Journal of Irrigation and Drainage Engineering, 134(3), 387399. doi:10.1061/(ASCE)0733-9437(2008)134:3(387).

Ren, C. F., Guo, P., Li, M., and Gu, J. J., 2013. Optimization of industrial structure considering the uncertainty of water resources. Water Resources Management, 27(11), 3885-3898. doi:10.1007/s11269-013-0385-1.

Rojas, R., Feyen, L., Dosio, A., and Bavera, D., 2011. Improving pan-European hydrological simulation of extremeeventsthrough statistical bias correction of RCM-driven climatesimulations. Hydrology and Earth System Sciences, 15(8), 2599-2620. doi:10.5194/hess-15-2599-2011.

Sargent, B. P., 2012. Water Use in Louisiana, 2010, Louisiana Department of Transportation and Development, Water Resources Special Report No. 17 (Revised), 135 p.

Schwarz, G., 1978. Estimating the dimension of a model. The Annals of Statistics, 6(2), 461464. 
801 Schaible, S., 1981. Fractional programming: applications and algorithms. European Journal of 802 Operational Research, 7(2), 111-120. doi:10.1016/0377-2217(81)90272-1.

803 Seager, R., Ting, M., Li, C., Naik, N., Cook, B., Nakamura, J., and Liu, H., 2013. Projections of 804 declining surface-water availability for the southwestern United States. Nature Climate Change, 3(5), 482-486. doi:10.1038/nclimate1787.

806 Singh, A., 2012. An overview of the optimization modelling applications. Journal of Hydrology, 807 466, 167-182. doi:10.1016/j.jhydrol.2012.08.004.

808 Singh, A., 2014. Conjunctive use of water resources for sustainable irrigated agriculture. Journal 809 of Hydrology, 519(B), 1688-1697. doi:10.1016/j.jhydrol.2014.09.049.

810 Smith, R. L., Tebaldi, C., Nychka, D., and Mearns, L. O., 2009. Bayesian modeling of uncertainty in ensembles of climate models. Journal of the American Statistical

813 Stocker, T., Dahe, Q., Plattner, G.-K., Tignor, M., and Midgley, P., 2010. IPCC expert meeting on assessing and combining multi model climate projections. National Center for Atmospheric Research, Boulder, Colorado, USA, 25-27.

816 Tamer Ayvaz, M., and Karahan, H., 2008. A simulation/optimization model for the identification of unknown groundwater well locations and pumping rates. Journal of Hydrology,

819 Tebaldi, C., Smith, R. L., Nychka, D., and Mearns, L. O., 2005. Quantifying uncertainty in projections of regional climate change: A Bayesian approach to the analysis of multimodel ensembles. Journal of Climate, 18(10), 1524-1540. doi:10.1175/JCLI3363.1. 
822 Theodossiou, N. P., 2004. Application of non-linear simulation and optimisation models in 823 groundwater aquifer management. Water Resources Management, 18(2), 125-141. doi:10.1023/B:WARM.0000024723.17916.64.

825 Thornton, P. E., Running, S. W., and White, M. A., 1997. Generating surfaces of daily meteorological variables over large regions of complex terrain. Journal of Hydrology,

828 Tsai, F. T.-C., and Li, X., 2008. Inverse groundwater modeling for hydraulic conductivity estimation using Bayesian model averaging and variance window. Water Resources Research, 44(9). doi:10.1029/2007wr006576.

USACE, 2015. U.S. Army Corps of Engineers, CorpsMap National Inventory of Dams, Reservoir data available on the World Wide Web, accessed March 2, 2016, at URL

834 Vetter, T., Huang, S., Aich, V., Yang, T., Wang, X., Krysanova, V., and Hattermann, F., 2015. Multi-model climate impact assessment and intercomparison for three large-scale river basins on three continents. Earth System Dynamics, 6(1), 17-43. doi:10.5194/esd-6-17-

Vogel, R. M., and Stedinger, J. R., 1987. Generalized storage-reliability-yield relationships.

840 Vogel, R. M., Lane, M., Ravindiran, R. S., and Kirshen, P., 1999. Storage reservoir behavior in the United States. Journal of Water Resources Planning and Management, 125(5), 245254. doi:10.1061/(ASCE)0733-9496(1999)125:5(245), 245-254. 
843 Vrugt, J. A., and Robinson, B. A., 2007. Treatment of uncertainty using ensemble methods:

844 Comparison of sequential data assimilation and Bayesian model averaging. Water

845 Resources Research, 43(1). doi:10.1029/2005WR004838.

846 Weiland, F. S., Van Beek, L. P. H., Weerts, A. H., and Bierkens, M. F. P., 2012. Extracting

847 information from an ensemble of GCMs to reliably assess future global runoff change.

$848 \quad$ Journal of Hydrology, 412, 66-75. doi:10.1016/j.jhydrol.2011.03.047.

849 Zhang, X., Srinivasan, R., and Bosch, D., 2009. Calibration and uncertainty analysis of the

850 SWAT model using genetic algorithms and Bayesian model averaging. Journal of $851 \quad$ Hydrology, 374(3-4), 307-317. doi:10.1016/j.jhydrol.2009.06.023.

852 Zhu, H., and Huang, G. H., 2011. SLFP: A stochastic linear fractional programming approach for 853 sustainable waste management. Waste Management, 31(12), 2612-2619. 854 doi:10.1016/j.wasman.2011.08.009. 


\section{Table Captions}

856 Table 1. Water demands at demand nodes (Sargent, 2012)

857 Table 2. Future seasonal runoff changes (2011-2049) in the Bayou D’Arbonne subbasin (HUC8

858 - 08040206) compared to the USGS WaterWatch runoff (1980-2005)

859 Table 3. Model weights and BIC values based on their similarity of interannual runoff variability

860 to the USGS WaterWatch dataset during the historical period (1980-2005) 
862 Fig. 1. (a) Areal extent of Sparta aquifer at top-right figure where solid circles are pumping wells

863 (modified from McKee and Clark, 2003) and watershed boundaries for the four lakes. Open

864 circles in the main map are USGS groundwater observation wells and open triangles are USGS

865 streamflow gauges. Solid circles in the main map are selected pumping centers. (b) Proposed

866 water supply network.

867 Fig. 2. Flowchart of the conjunctive management model.

868 Fig. 3. Comparison of VIC simulated monthly runoff (mm) to USGS WaterWatch monthly

869 runoff for (a) Loggy Bayou subbasin and (b) Bayou D’Arbonne subbasin. Comparison of VIC

870 simulated monthly streamflow $\left(\mathrm{m}^{3} / \mathrm{s}\right)$ to USGS streamflow at gauges (c) Bayou Dorcheat near

871 Springhill, LA (Station Number: 07348700) and (d) Little Corney Bayou near Lillie, LA (Station

872 Number: 07366200). NSE = Nash-Sutcliffe efficiency, RMSE = root mean square error, and $\mathrm{R}^{2}=$

873 square of correlation coefficient.

874 Fig. 4. Scatter plots of projected mean annual temperature and precipitation changes for 97

875 statistically downscaled CMIP5 GCM projections (BCSD) under four emission scenarios (RCP

$8762.6,4.5,6.0$, and 8.5; green symbols) and the 11 RegCM4 simulations (blue symbols) used in

877 this study. Change is defined as the degree change of average temperature (C) and percentage

878 change of average precipitation (\%) from 1966-2005 baseline to 2011-2050 future periods in the

879 study area. The 97 climate projections were obtained from the BCSD data archive (Brekke et al., $880 \quad 2013)$.

881 Fig. 5. Cumulative probability of simulated runoff from 11 hydro-climate models and the USGS

882 WaterWatch data in 1980-2005. 
883 Fig. 6. BMA mean monthly runoff (mm) and 95\% confidence interval for (a) Loggy Bayou 884 subbasin, (b) Bayou D’Arbonne subbasin for historical period (1980-2005), (c) Loggy Bayou 885 subbasin, and (d) Bayou D’Arbonne subbasin for future period (2011-2025).

886 Fig. 7. Low inflow projections at 2.5\%, 10\%, and 50\% cumulative probability levels for (a) 887 Corney Lake, (b) Bayou D’Arbonne Lake, (c) Lake Claiborne, and (d) Lake Bistineau for future 888 period (2011-2025).

889 Fig. 8. Optimized storage distributions with 2.5\%, 10\%, and 50\% low inflow projections for 890 future period (2011-2025).

891 Fig. 9. Optimized spills from the four reservoirs for future period (2011-2025).

892 Fig. 10. Pumping rates for Ouachita wells (a) for 2001-2010 and (b) 2011-2025 optimized.

893 Pumping rates for Union and Lincoln wells (c) for 2001-2010 and (d) 2011-2025 optimized.

894 Fig. 11. Groundwater levels (m) above NGVD 1929 at six selected USGS wells for future period $895 \quad(2011-2025)$.

896 Fig. 12. Optimized surface water and groundwater supplies given $2.5 \%, 10 \%$, and $50 \%$ low 897 inflow projections for (a) Monroe (water re-use supply in West Monroe is subtracted from the 898 total demand) and (b) Farmerville.

899 Fig. 13. Optimized surface water and groundwater supplies under $2.5 \%, 10 \%$, and $50 \%$ low 900 reservoir inflow projections for Ruston and Arcadia. 
1 Table 1. Water demands at demand nodes (Sargent, 2012)

2

\begin{tabular}{ccccccc}
\hline City & $\begin{array}{c}\text { Farmerville } \\
\left(\mathrm{D}_{1}\right)\end{array}$ & $\begin{array}{c}\text { Monroe } \\
\left(\mathrm{D}_{2}\right)\end{array}$ & $\begin{array}{c}\text { Ruston } \\
\left(\mathrm{D}_{3}\right)\end{array}$ & $\begin{array}{c}\text { Arcadia } \\
\left(\mathrm{D}_{4}\right)\end{array}$ & $\begin{array}{c}\text { Homer } \\
\left(\mathrm{D}_{5}\right)\end{array}$ & $\begin{array}{c}\text { Minden } \\
\left(\mathrm{D}_{6}\right)\end{array}$ \\
\hline $\begin{array}{c}\text { Demand } \\
\left(\mathrm{m}^{3} / \text { day }\right)\end{array}$ & 13,892 & 184,047 & 32,365 & 16,315 & 8,858 & 26,763 \\
\hline
\end{tabular}


1 Table 2. Future seasonal runoff changes (2011-2049) in the Bayou D'Arbonne subbasin (HUC8

2 - 08040206) compared to the USGS WaterWatch runoff (1980-2005)

3

\begin{tabular}{lrrrrrrrr}
\hline \multirow{2}{*}{ Model name } & \multicolumn{3}{c}{ Change in average runoff $(\%)$} & \multicolumn{3}{c}{ Change in median runoff (\%) } \\
\cline { 2 - 10 } & \multicolumn{1}{c}{ DJF } & MAM & \multicolumn{1}{c}{ JJA } & \multicolumn{1}{c}{ SON } & \multicolumn{1}{c}{ DJF } & MAM & JJA & SON \\
\hline ACCESS1-0 & -53.1 & -1.9 & 12.0 & 25.8 & -67.0 & -3.3 & 14.5 & 16.4 \\
BCC-CSM1-1 & -25.3 & 18.3 & 12.2 & 36.7 & -52.6 & 32.2 & 17.1 & 19.3 \\
CCSM4 & -32.7 & 68.1 & 19.2 & 24.2 & -75.8 & 91.1 & 29.4 & 19.5 \\
CMCC-CM & -11.2 & 16.4 & 24.3 & 29.1 & -23.4 & 32.3 & 28.2 & 29.3 \\
FGOALS-G2 & -112.2 & -52.6 & 17.7 & 0.9 & -134.4 & -28.5 & 33.3 & 7.9 \\
GFDL-ESM2M & 28.1 & 11.0 & 13.7 & 17.8 & -8.3 & 13.6 & 19.2 & 15.2 \\
IPSL-CM5A-LR & 6.9 & 30.5 & 19.4 & 25.0 & 6.2 & 46.9 & 25.4 & 29.5 \\
MIROC5 & -53.1 & 9.2 & 26.4 & 24.5 & -68.4 & 19.3 & 29.9 & 33.9 \\
MPI-ESM-MR & 22.4 & 5.8 & 15.9 & 23.6 & 16.4 & 22.0 & 27.0 & 22.6 \\
MRI-CGCM3 & -0.1 & 44.3 & 28.8 & 19.0 & -14.3 & 46.8 & 32.2 & 22.2 \\
Nor-ESM1-M & -41.6 & -25.8 & 16.6 & 14.3 & -45.6 & -25.9 & 30.2 & 14.5 \\
\hline BMA & -19.3 & 42.6 & 20.4 & 29.1 & -47.6 & 57.2 & 34.2 & 29.5 \\
\hline
\end{tabular}

4 
1 Table 3. Model weights and BIC values based on their similarity of interannual runoff variability 2 to the USGS WaterWatch dataset during the historical period (1980-2005)

3

\begin{tabular}{lccc}
\hline Model name & $\begin{array}{c}\text { Ensemble } \\
\text { member }\end{array}$ & Model weights & BIC \\
\hline ACCESS1-0 & r1p1i1 & 0.072 & 597.61 \\
BCC-CSM1-1 & r1p1i1 & 0.127 & 578.68 \\
CCSM4 & r6p1i1 & 0.461 & 535.86 \\
CMCC-CM & r1p1i1 & 0.011 & 661.05 \\
FGOALS-G2 & r1p1i1 & 0.038 & 619.09 \\
GFDL-ESM2M & r1p1i1 & 0.032 & 624.11 \\
IPSL-CM5A-LR & r1p1i1 & 0.020 & 640.70 \\
MIROC5 & r1p1i1 & 0.086 & 591.57 \\
MPI-ESM-MR & r1p1i1 & 0.001 & 728.84 \\
MRI-CGCM3 & r1p1i1 & 0.004 & 690.75 \\
Nor-ESM1-M & r1p1i1 & 0.148 & 573.74 \\
\hline
\end{tabular}

4 


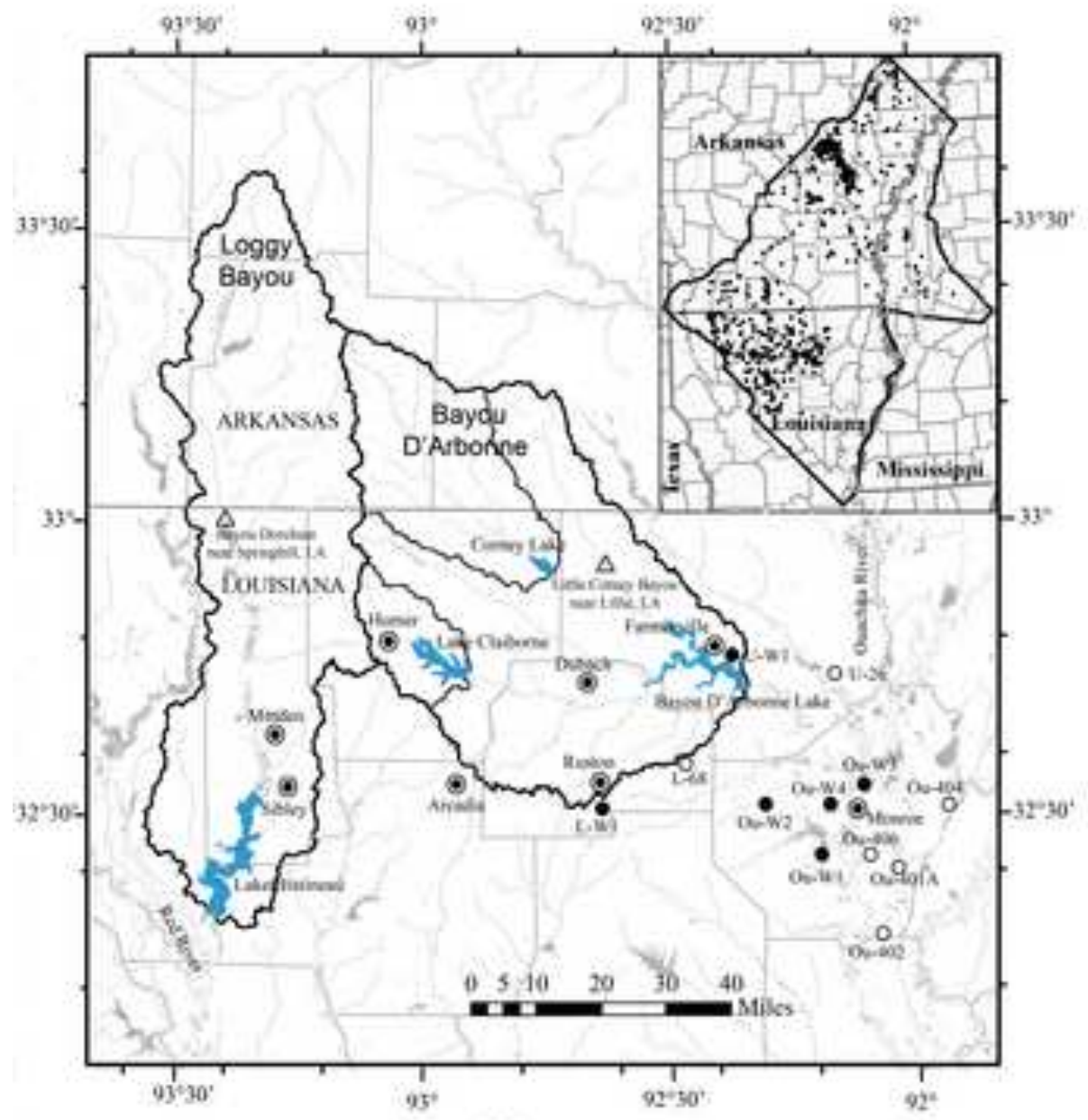

(a)

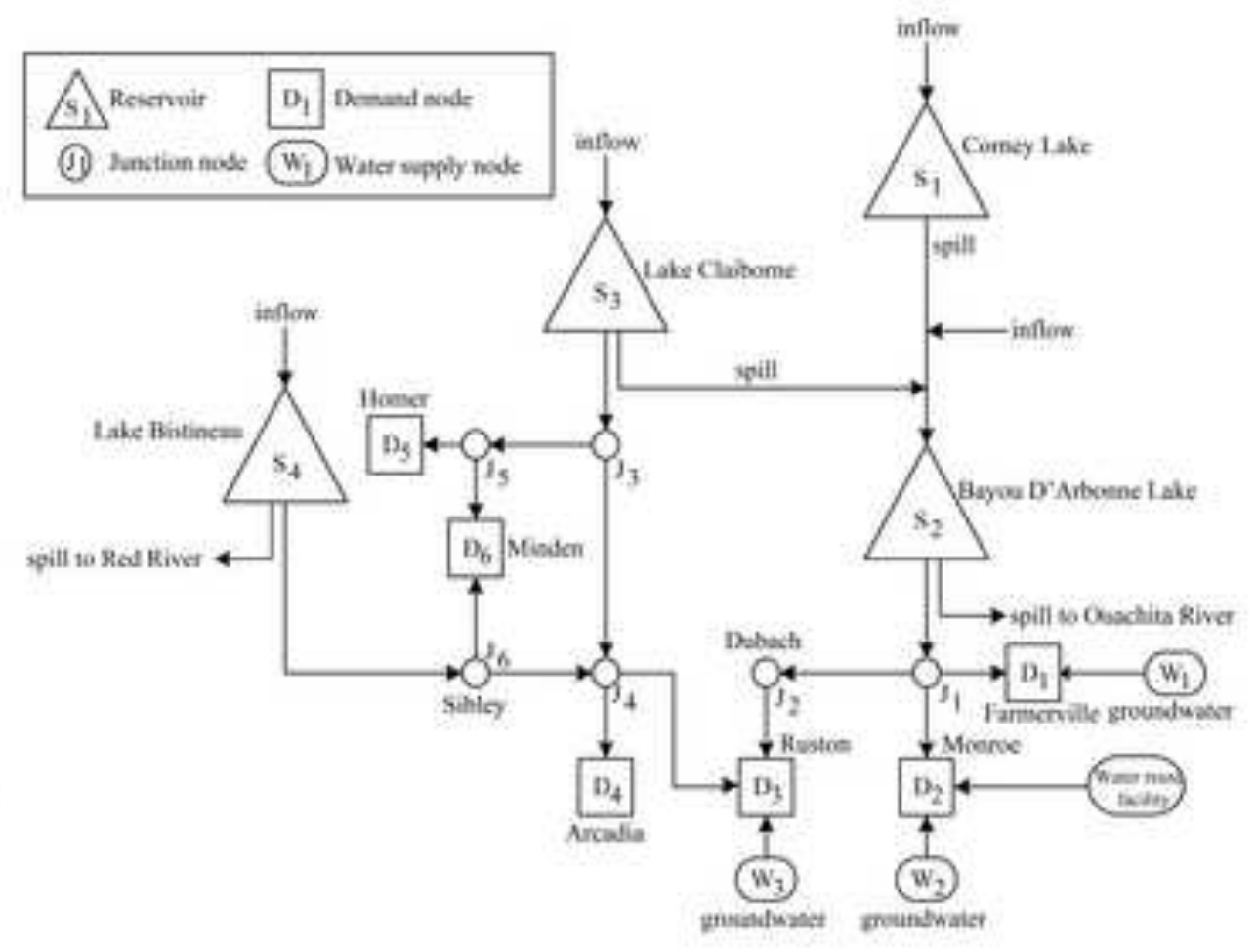

(b) 
Groundwater Modeling

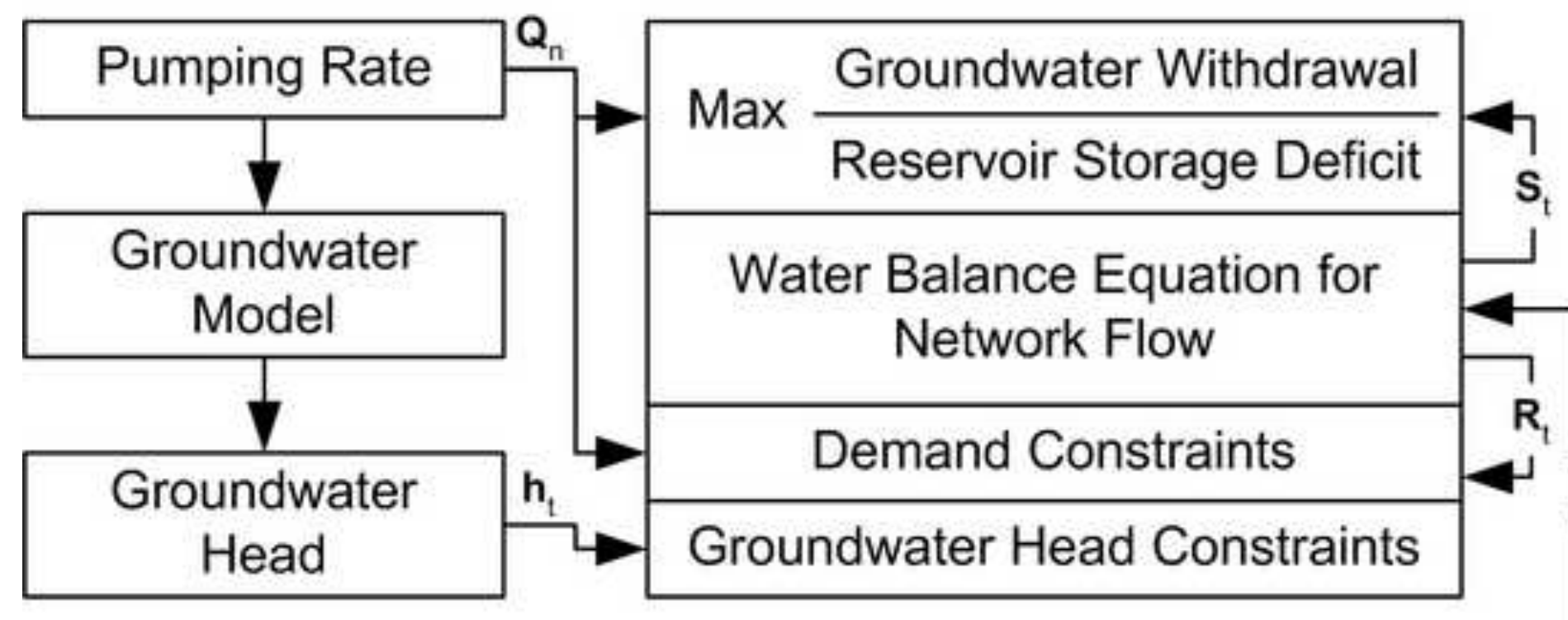

Hydrologic Modeling

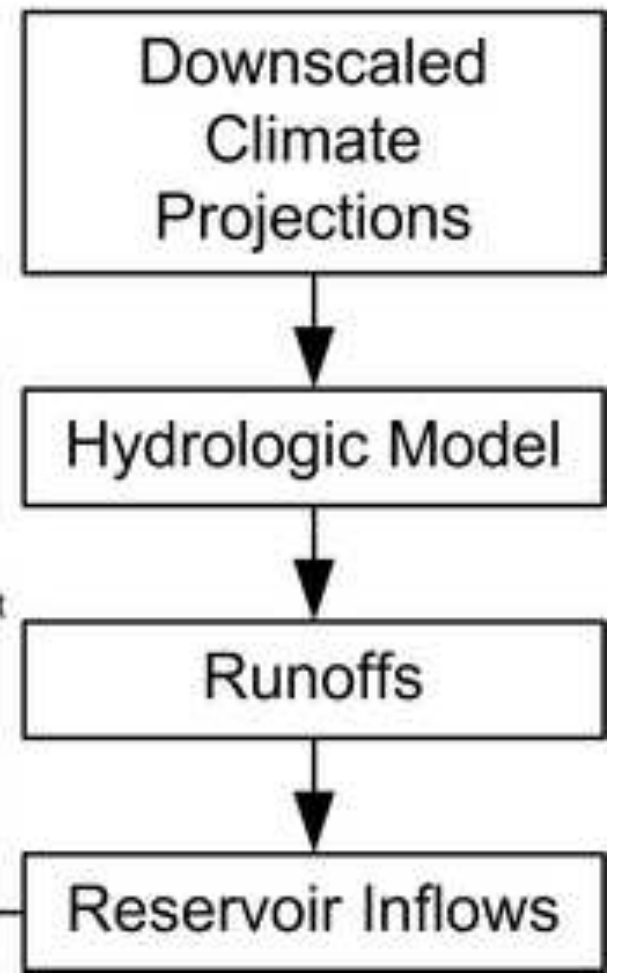




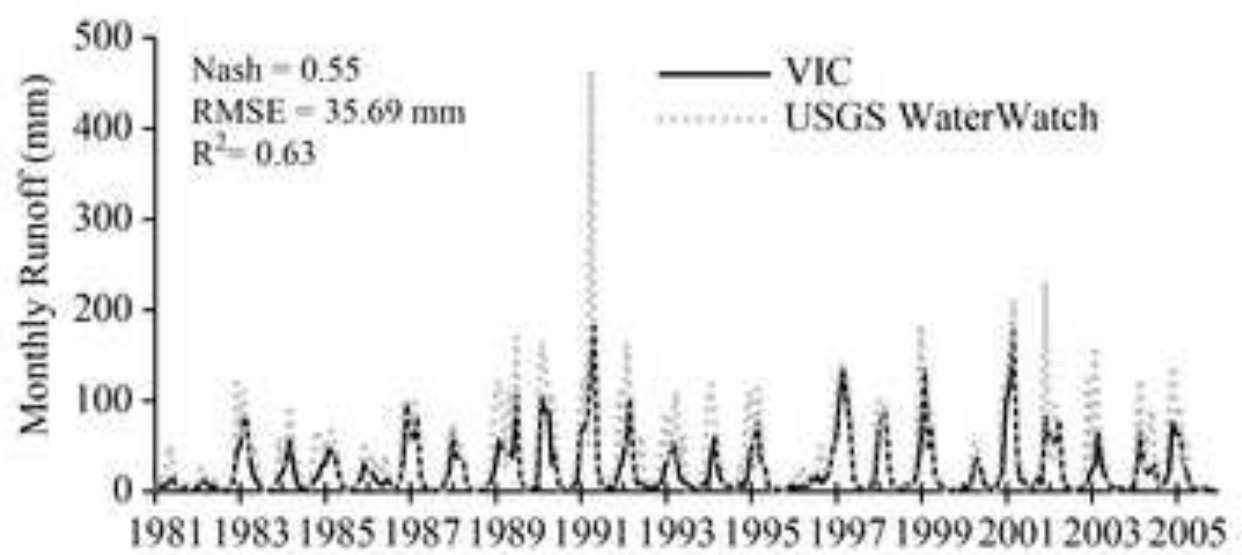

Loggy Bayou Subbasin

(a)

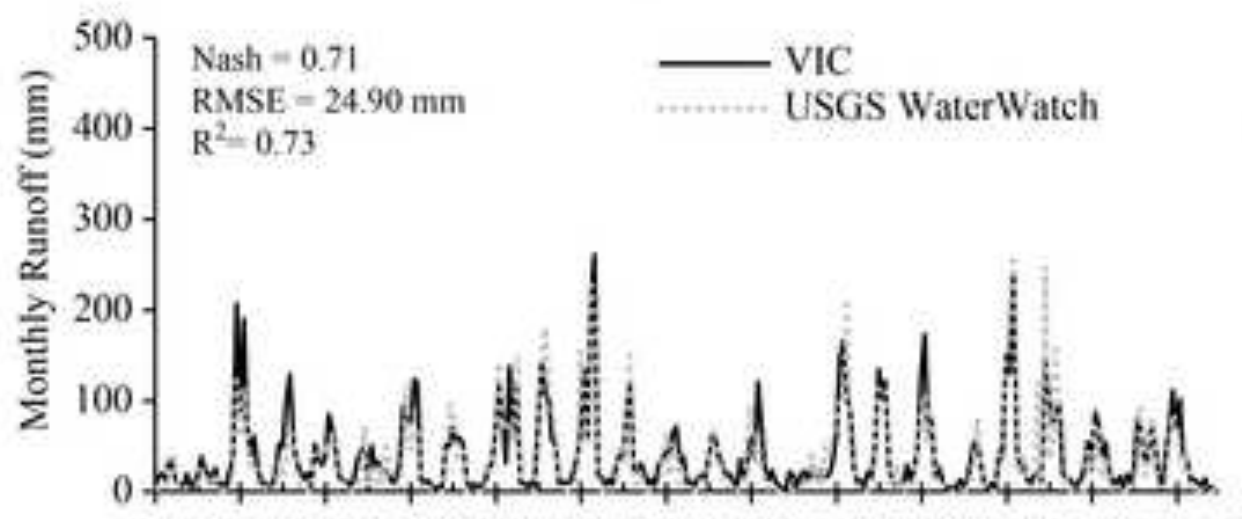

1981198319851987198919911993199519971999200120032005

Bayou D'Arbonne Subbasin

(b)

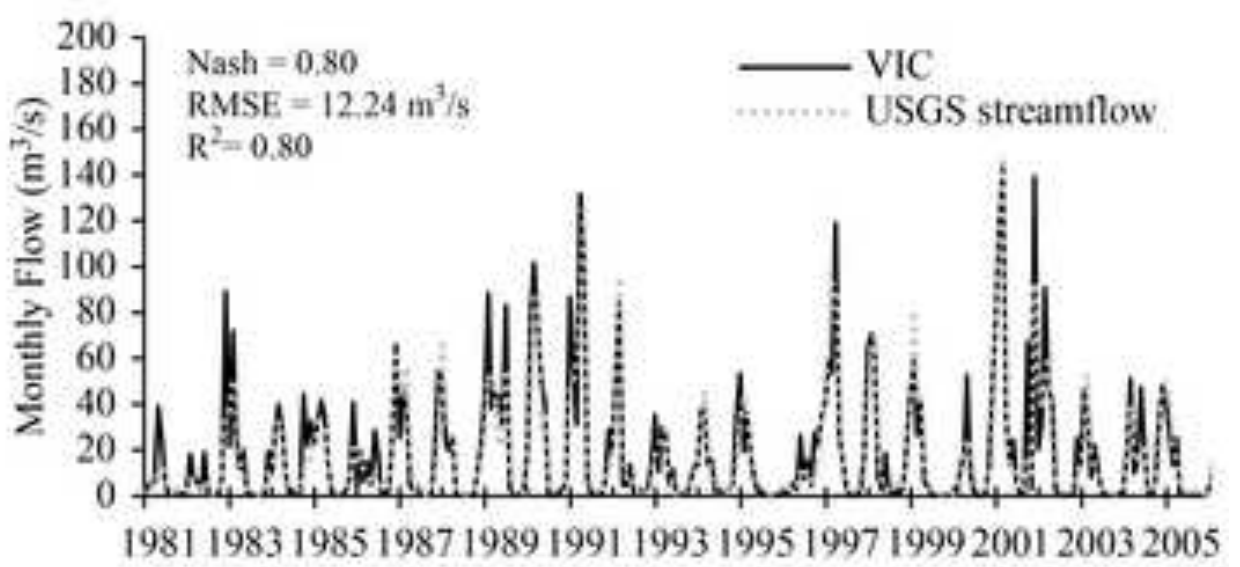

Bayou Dorcheat near Springhill, LA (07348700)

(c)

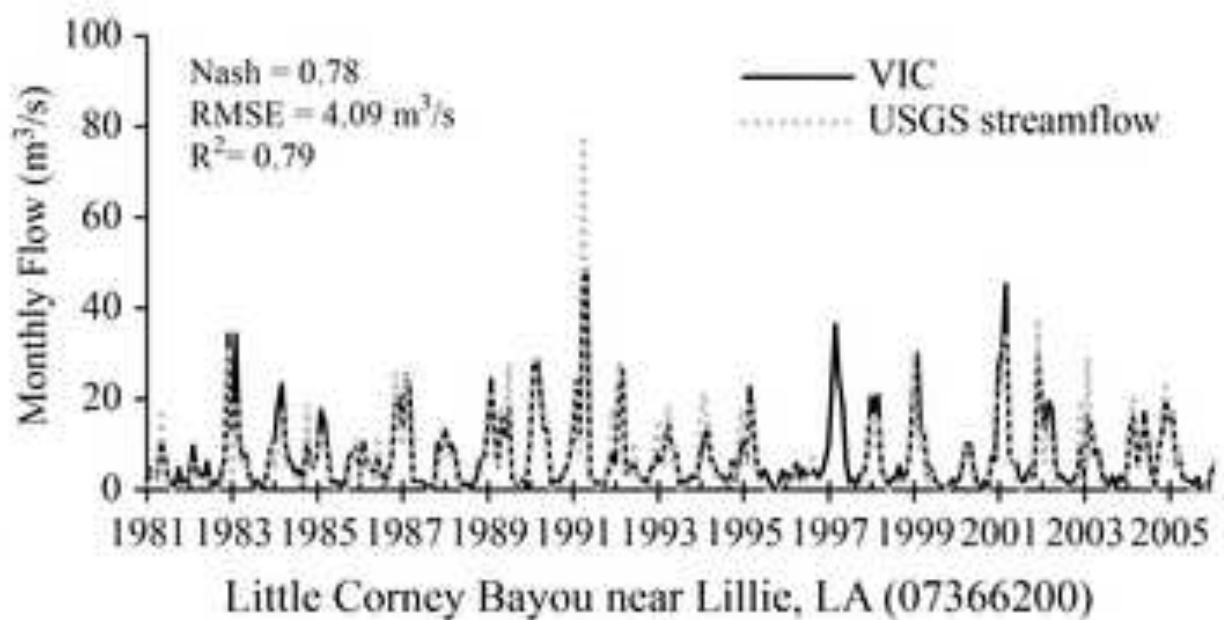

(d) 


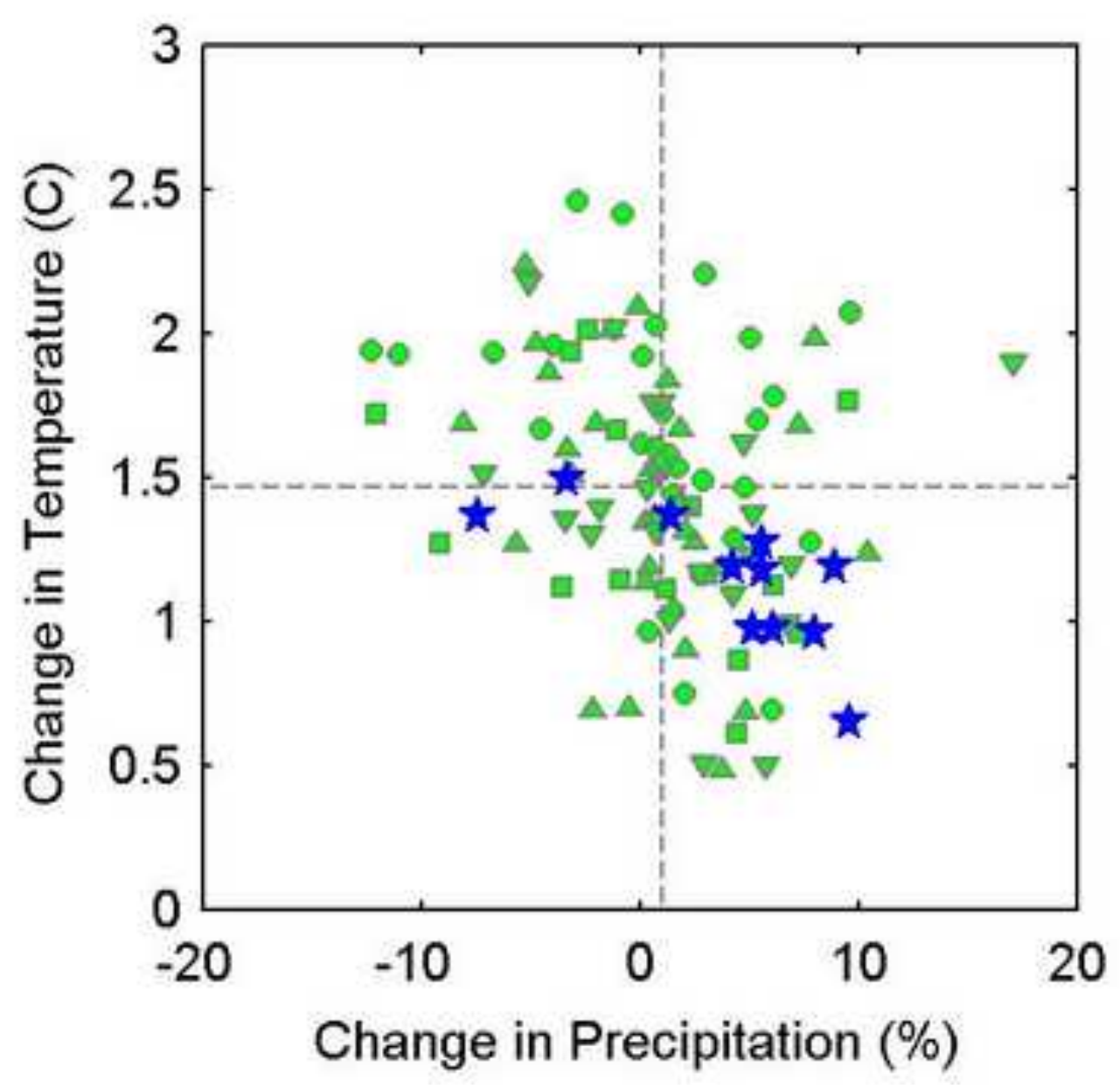

\begin{tabular}{|ll|}
\hline$\bullet$ & BCSD5-RCP8.5 (29) \\
$\star$ & BCSD5-RCP6.0 (16) \\
$\star$ & BCSD5-RCP4.5 (31) \\
$\nabla$ & BCSD5-RCP2.6 (21) \\
$\star$ & RegCM-RCP8.5 (11) \\
\hdashline & Median BCSD5 \\
\hline
\end{tabular}

Change in Precipitation (\%) 


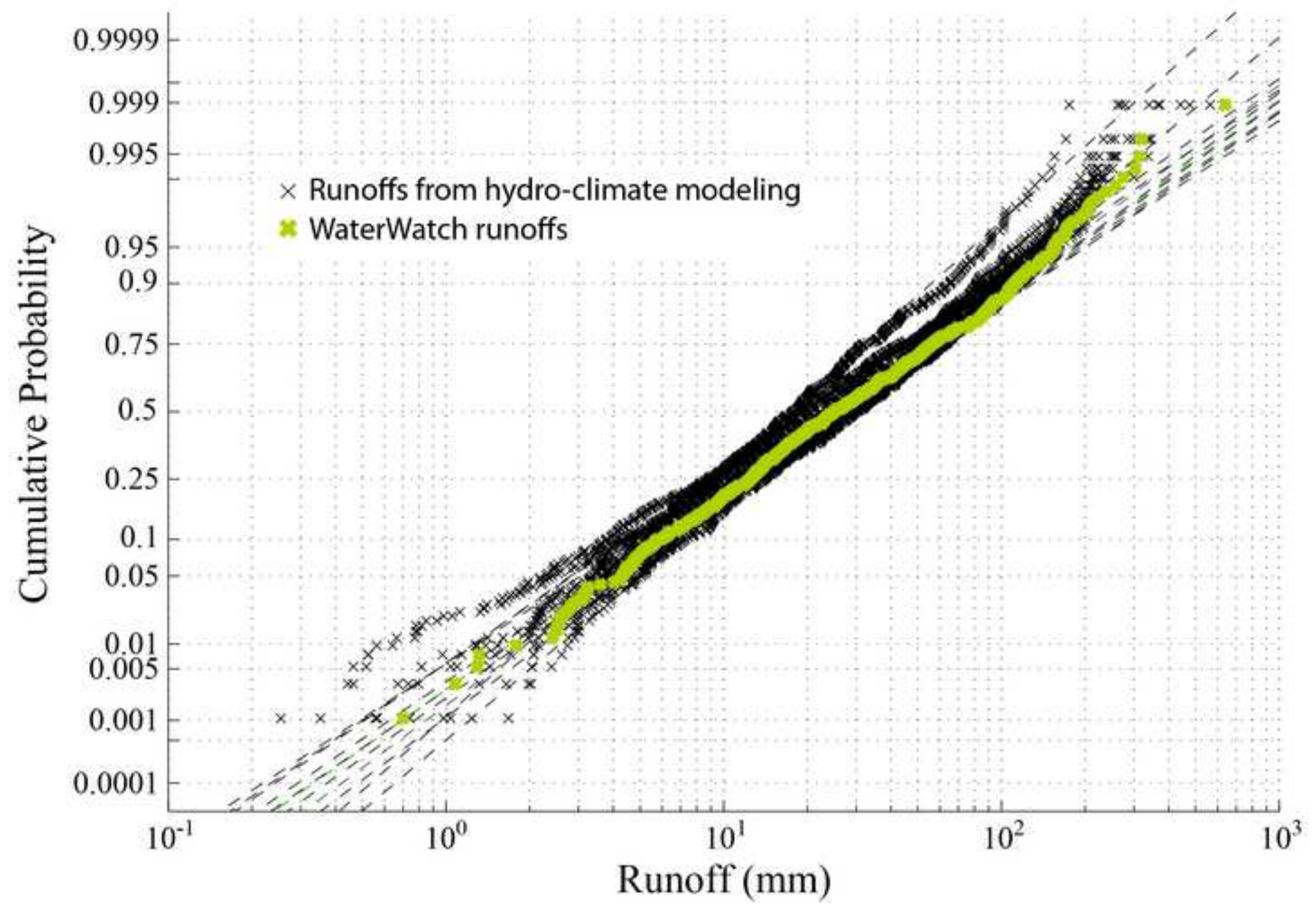




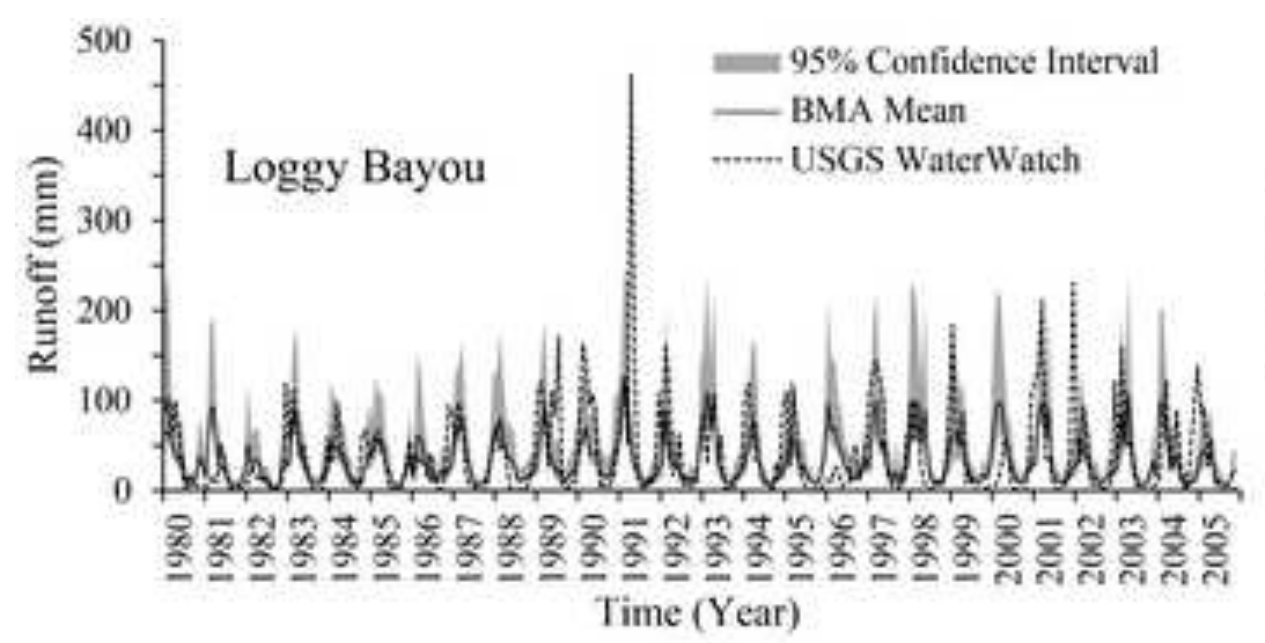

(a)

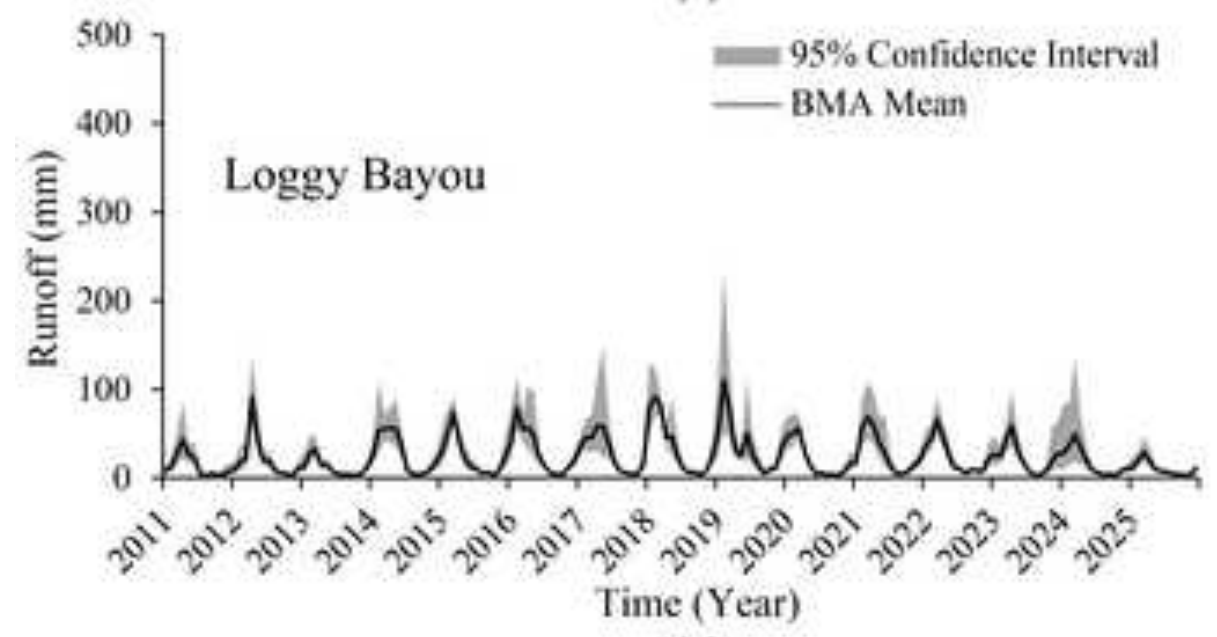

(c)

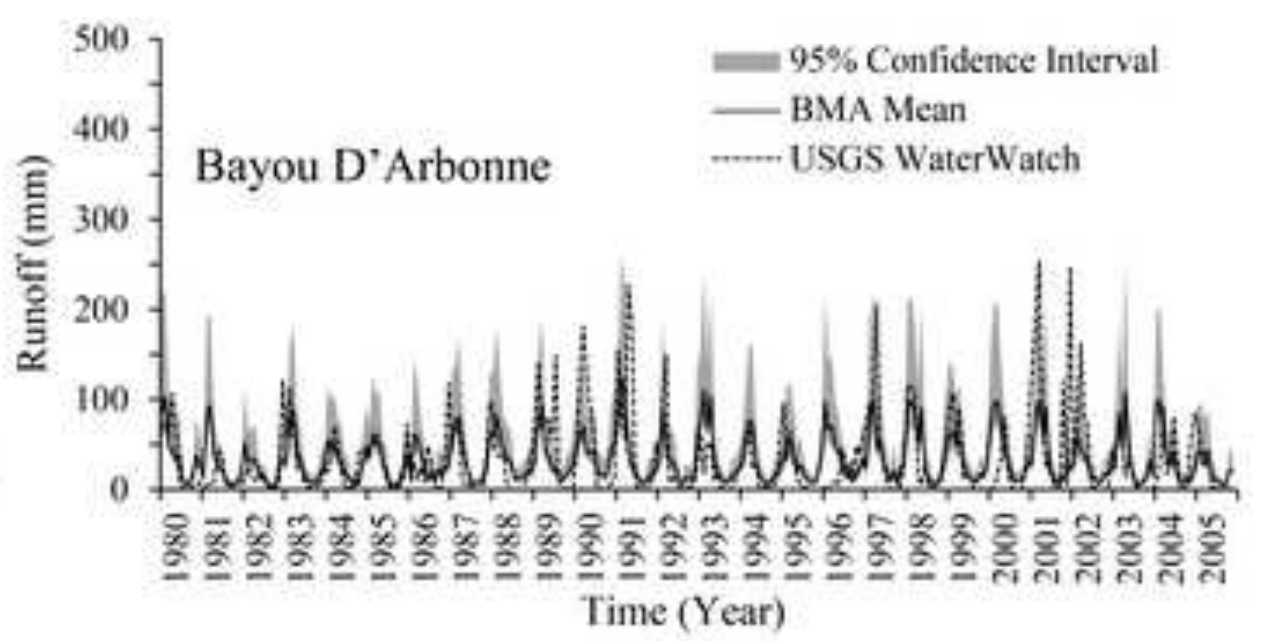

(b)

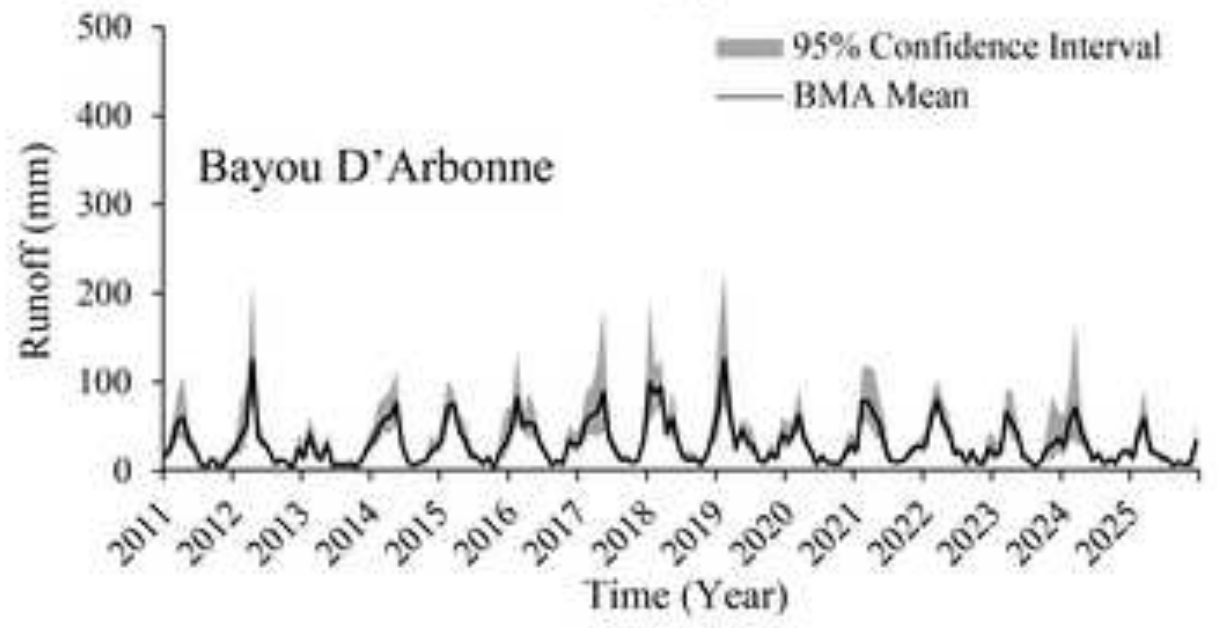

(d) 


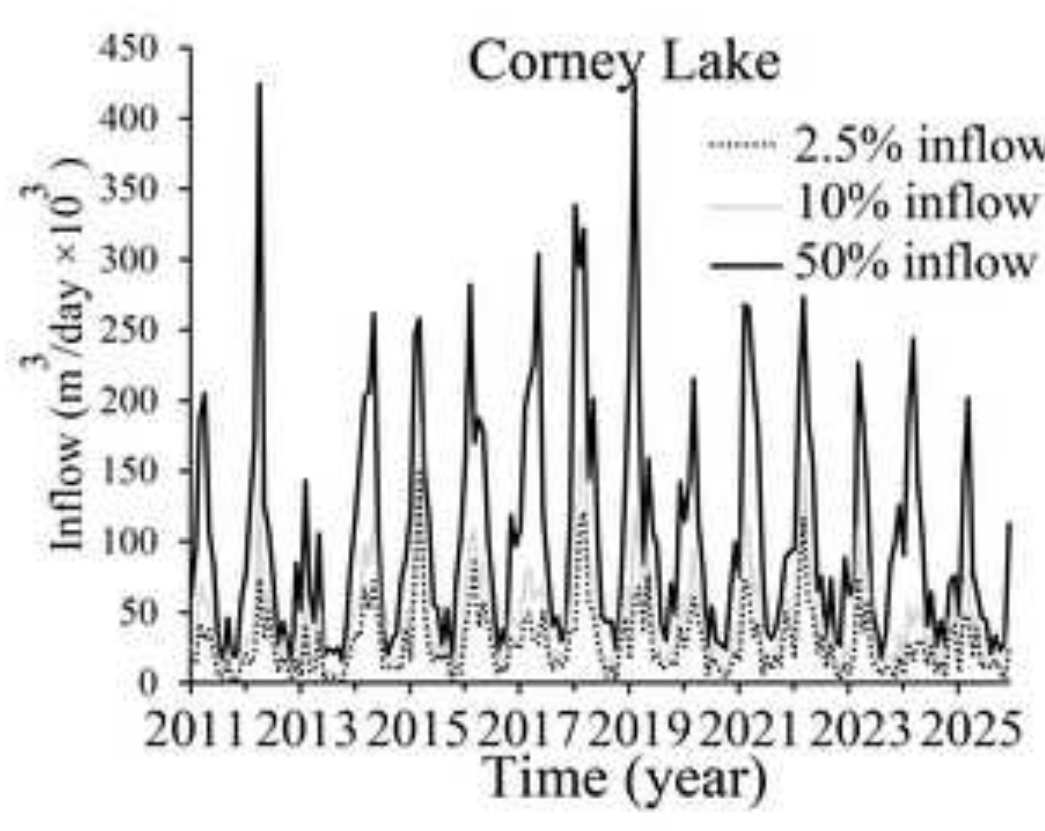

(a)

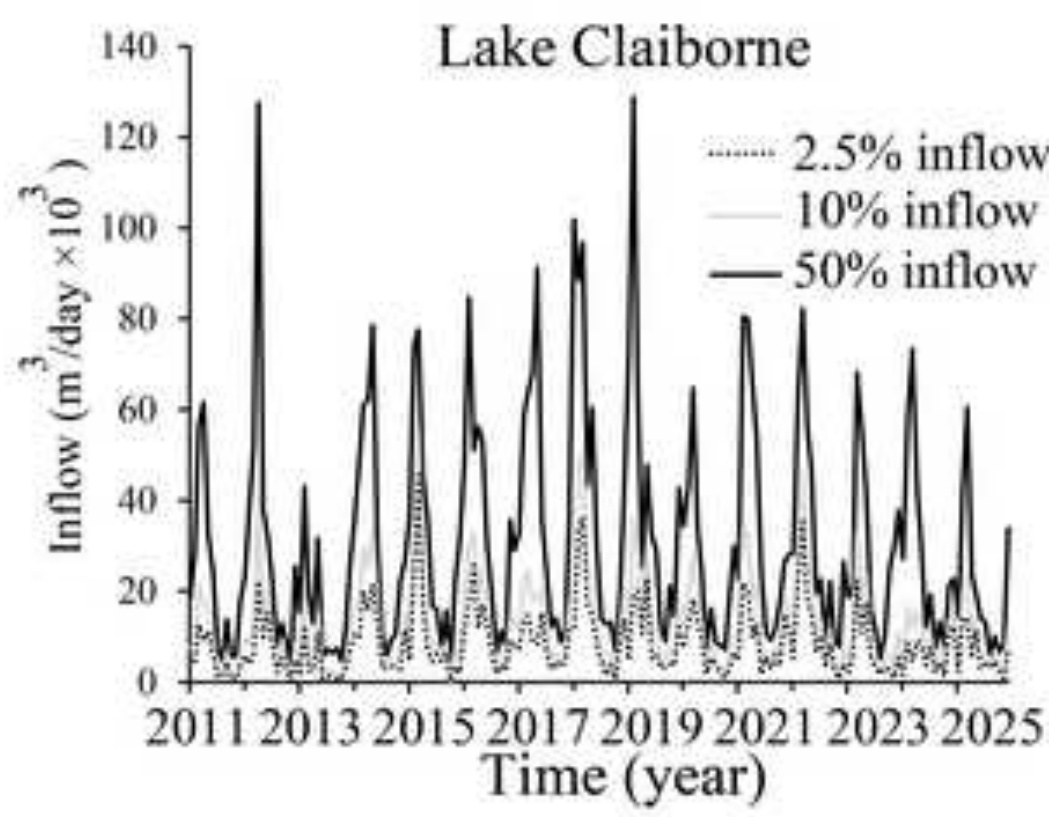

(c)

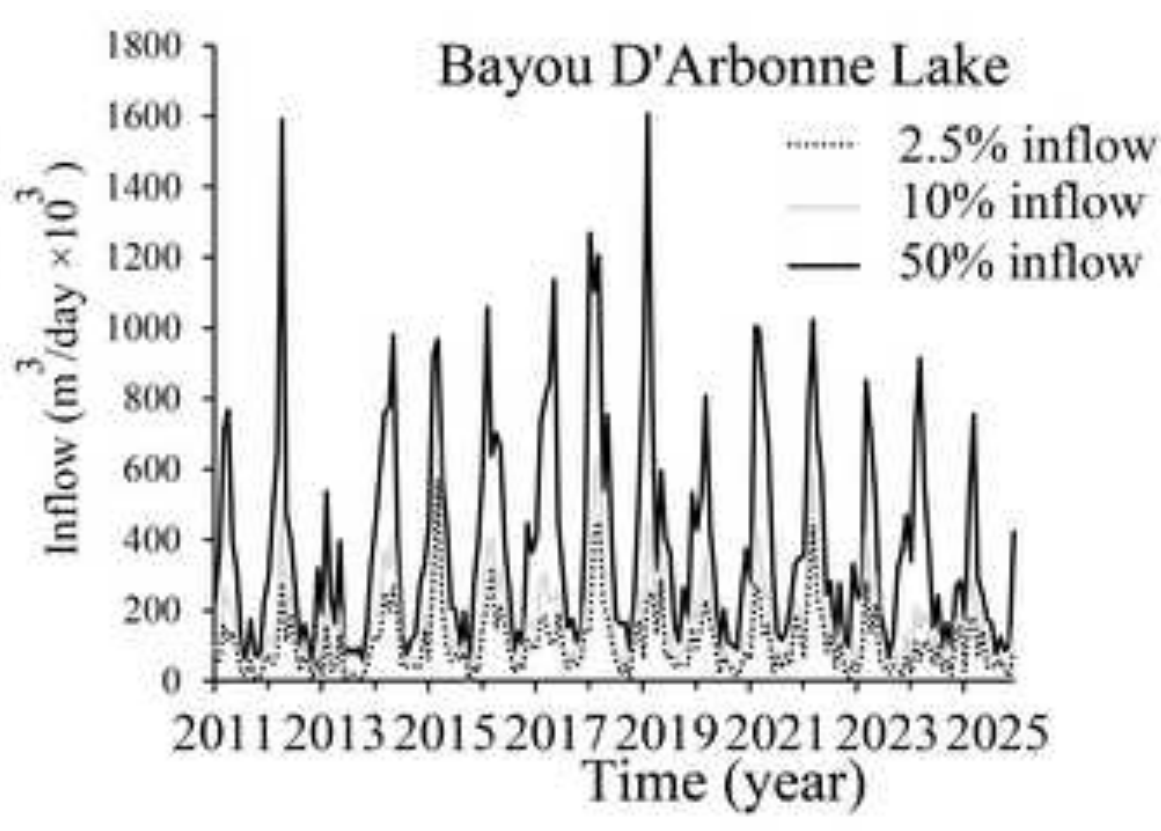

(b)

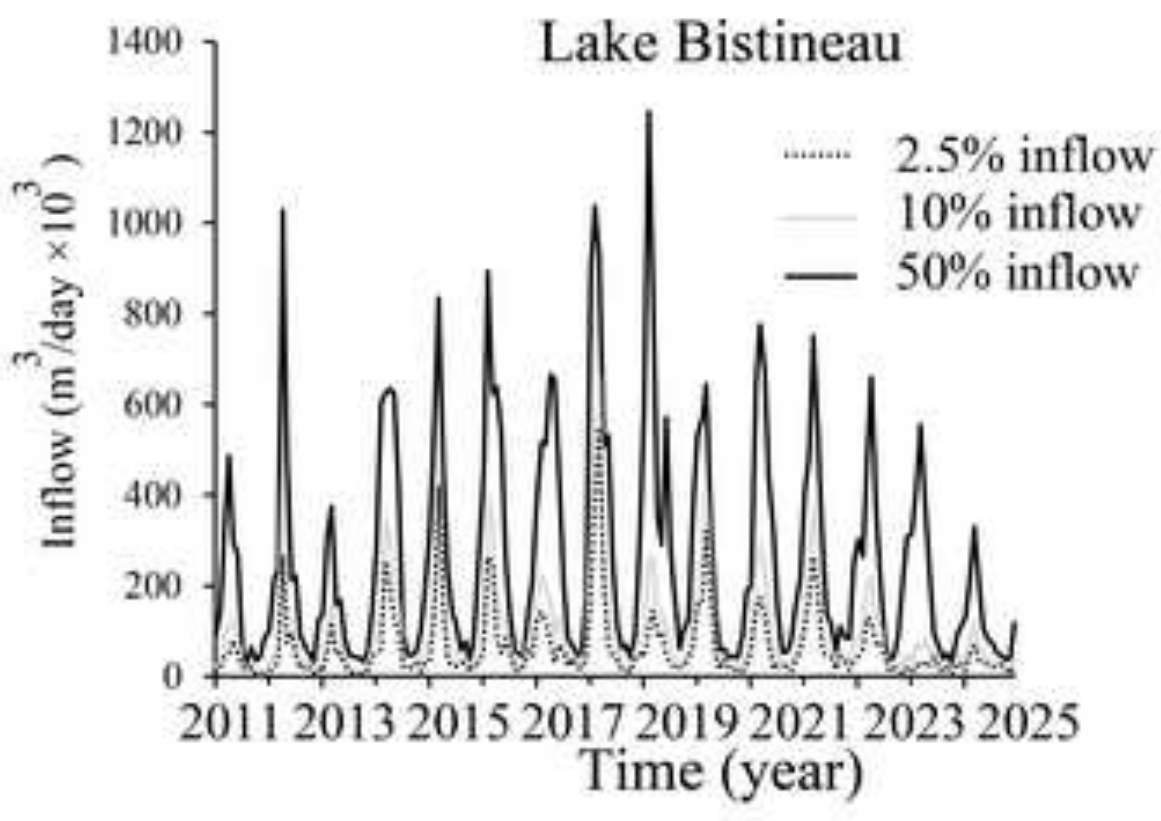

(d) 


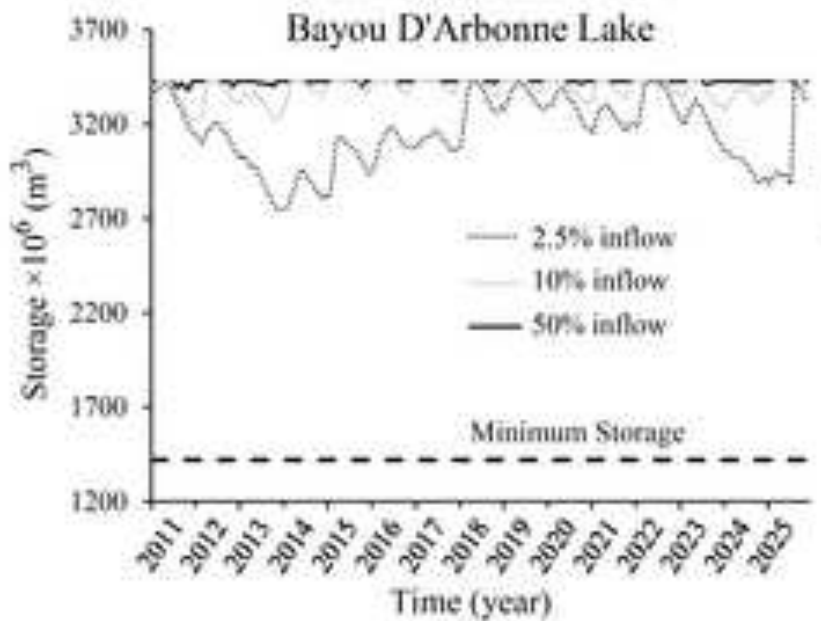

(a)

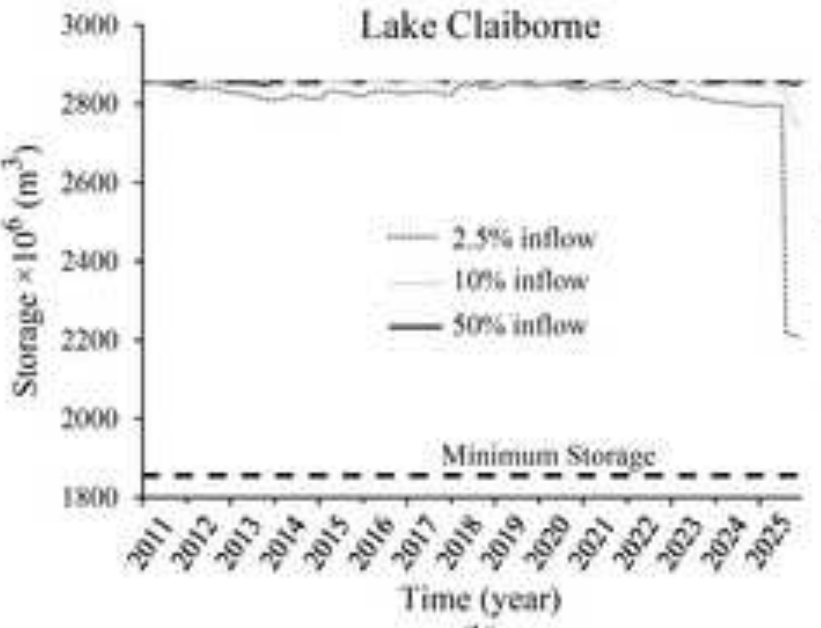

(b)

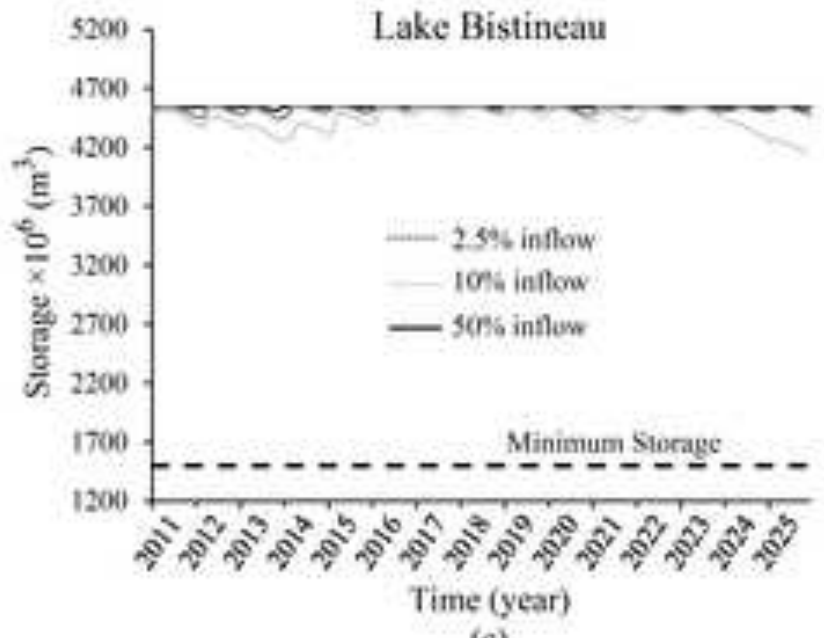

(c) 


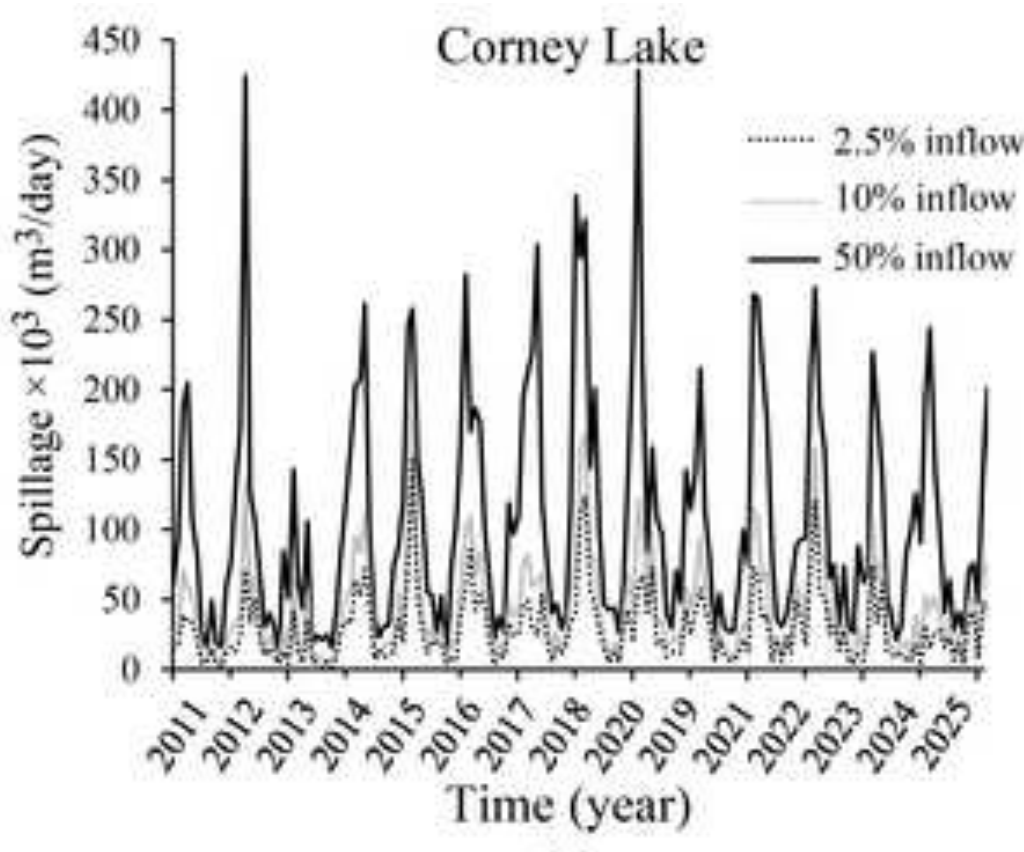

(a)

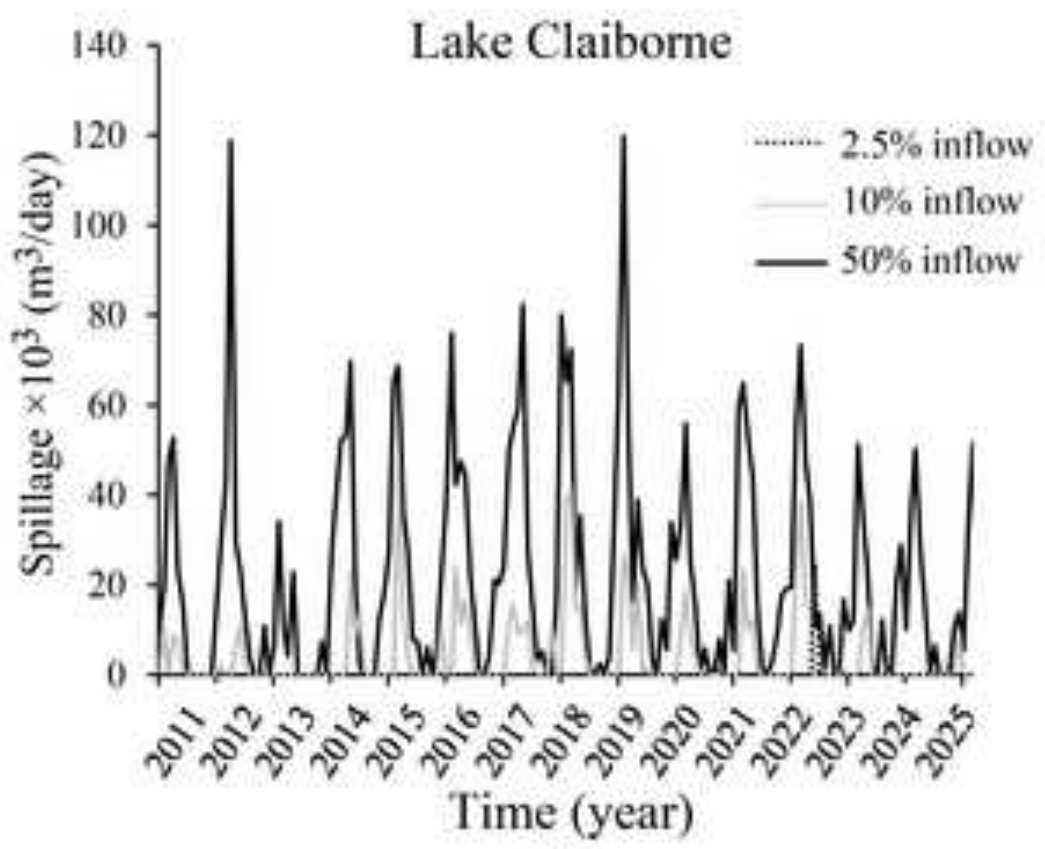

(c)

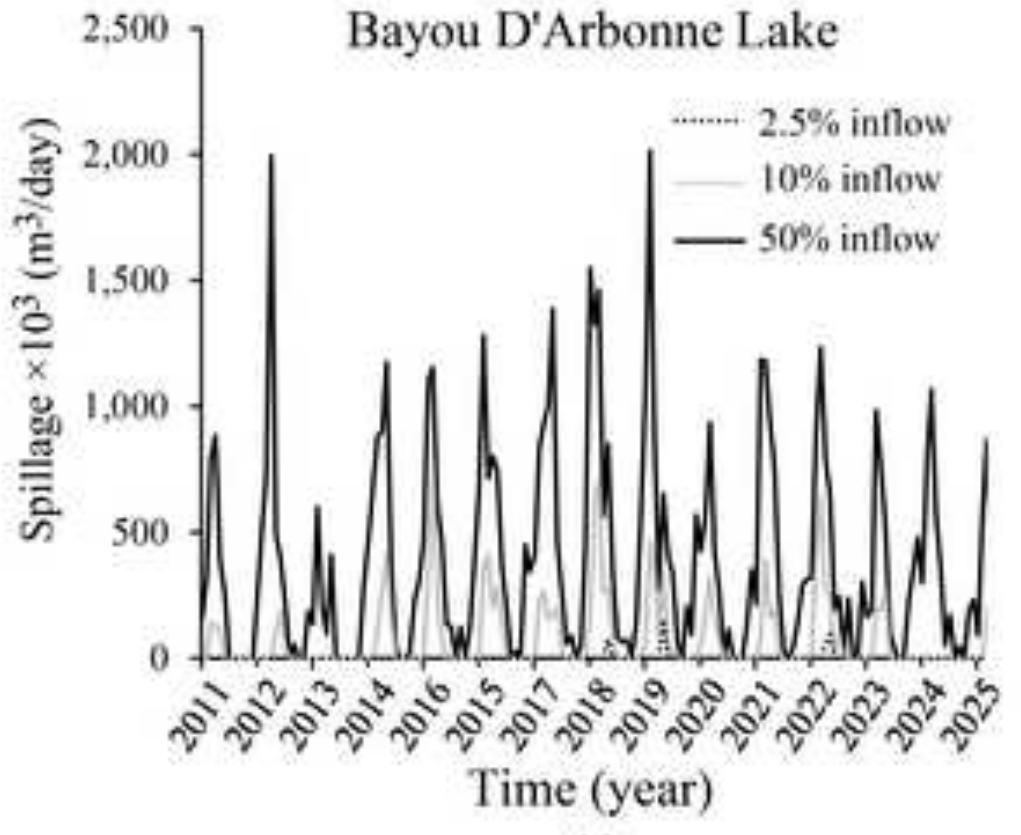

(b)

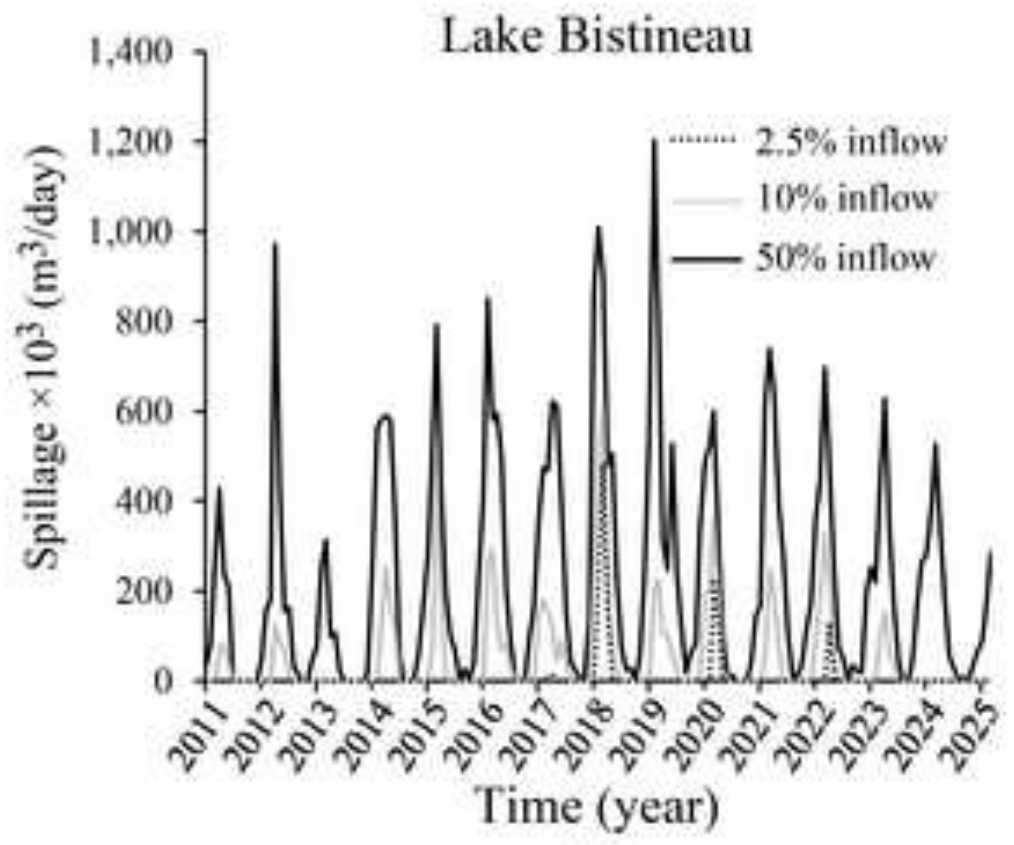

(d) 


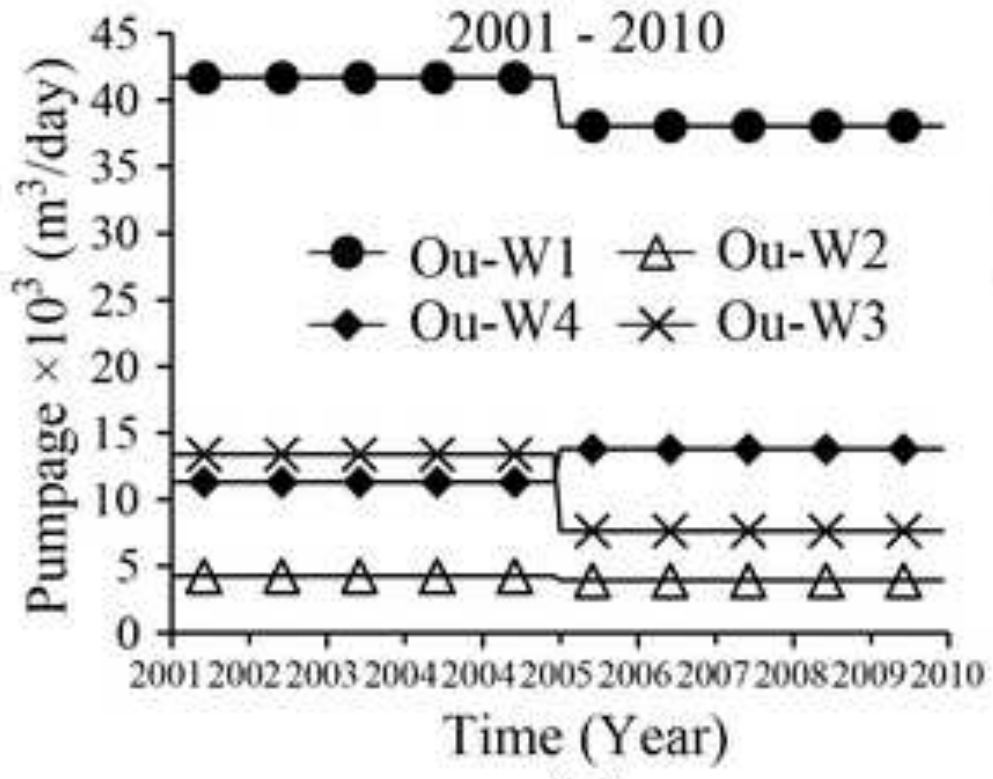

(a)

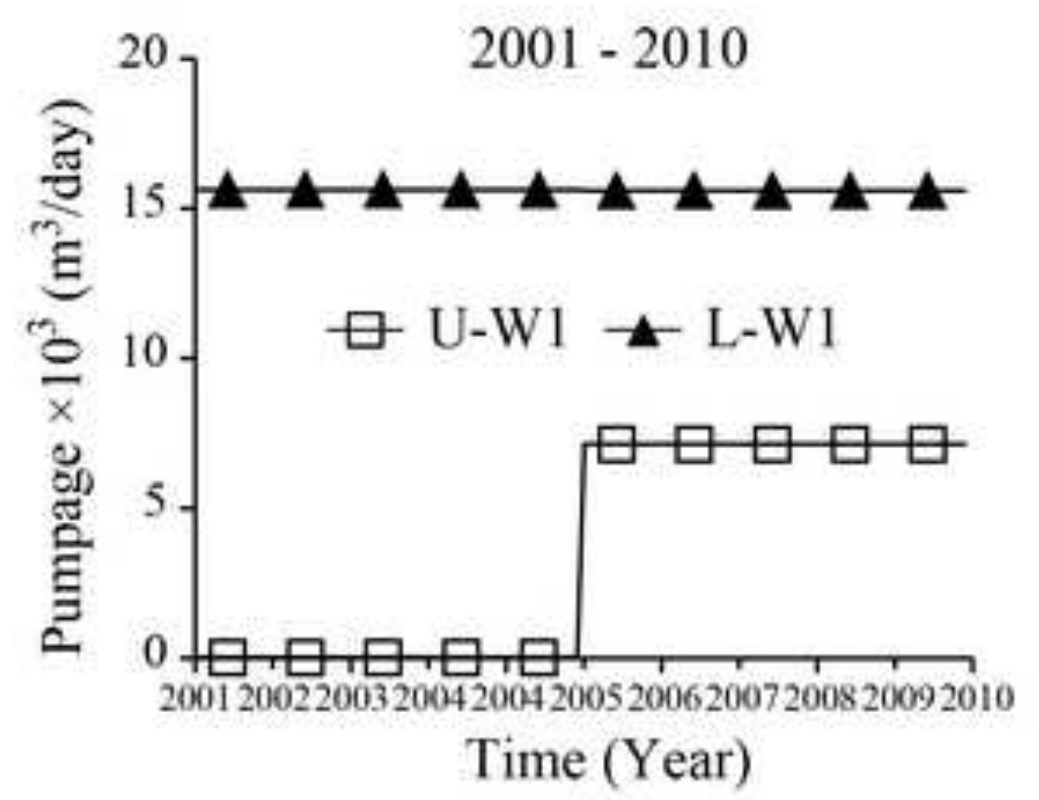

(c)

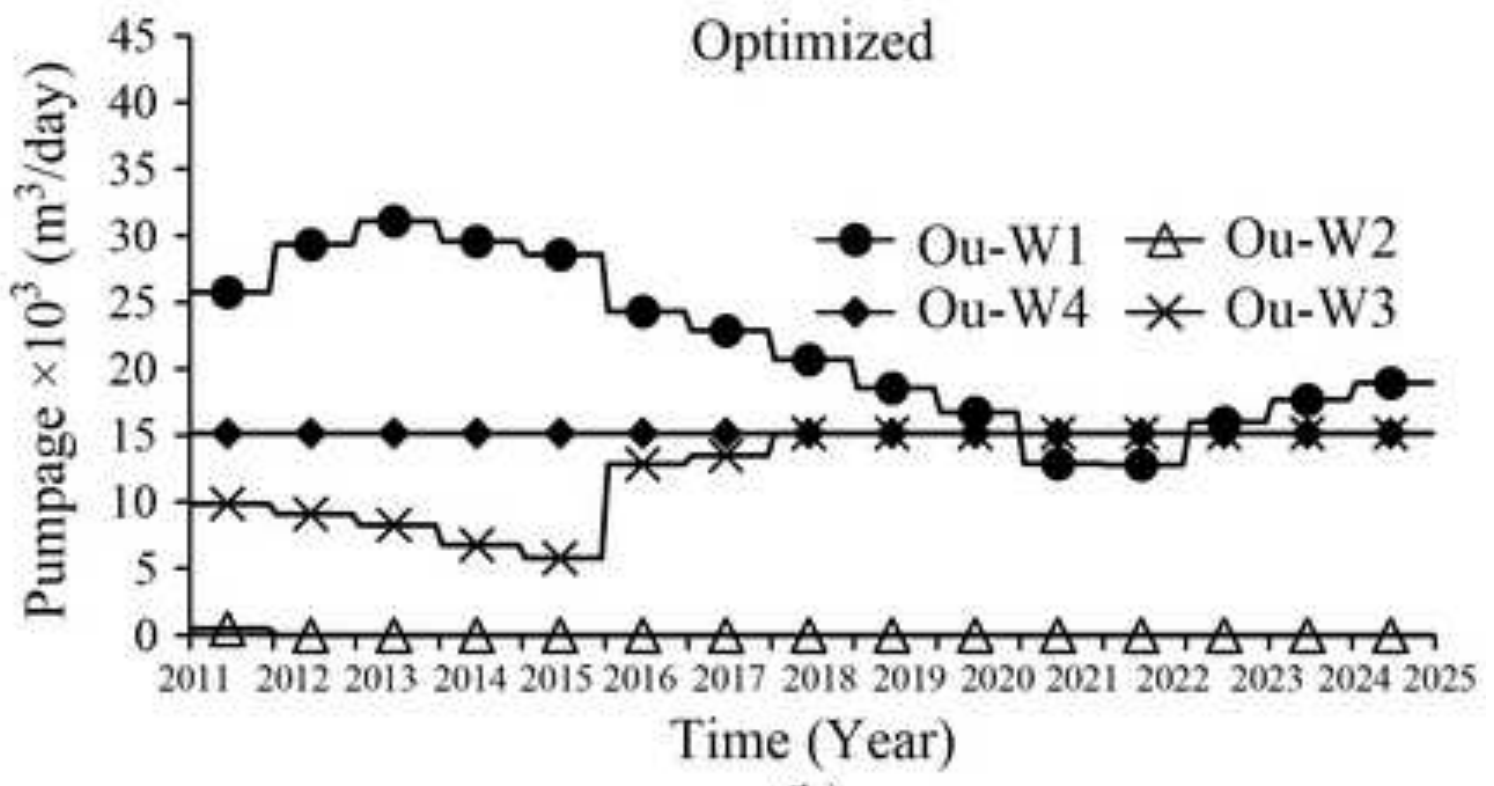

(b)

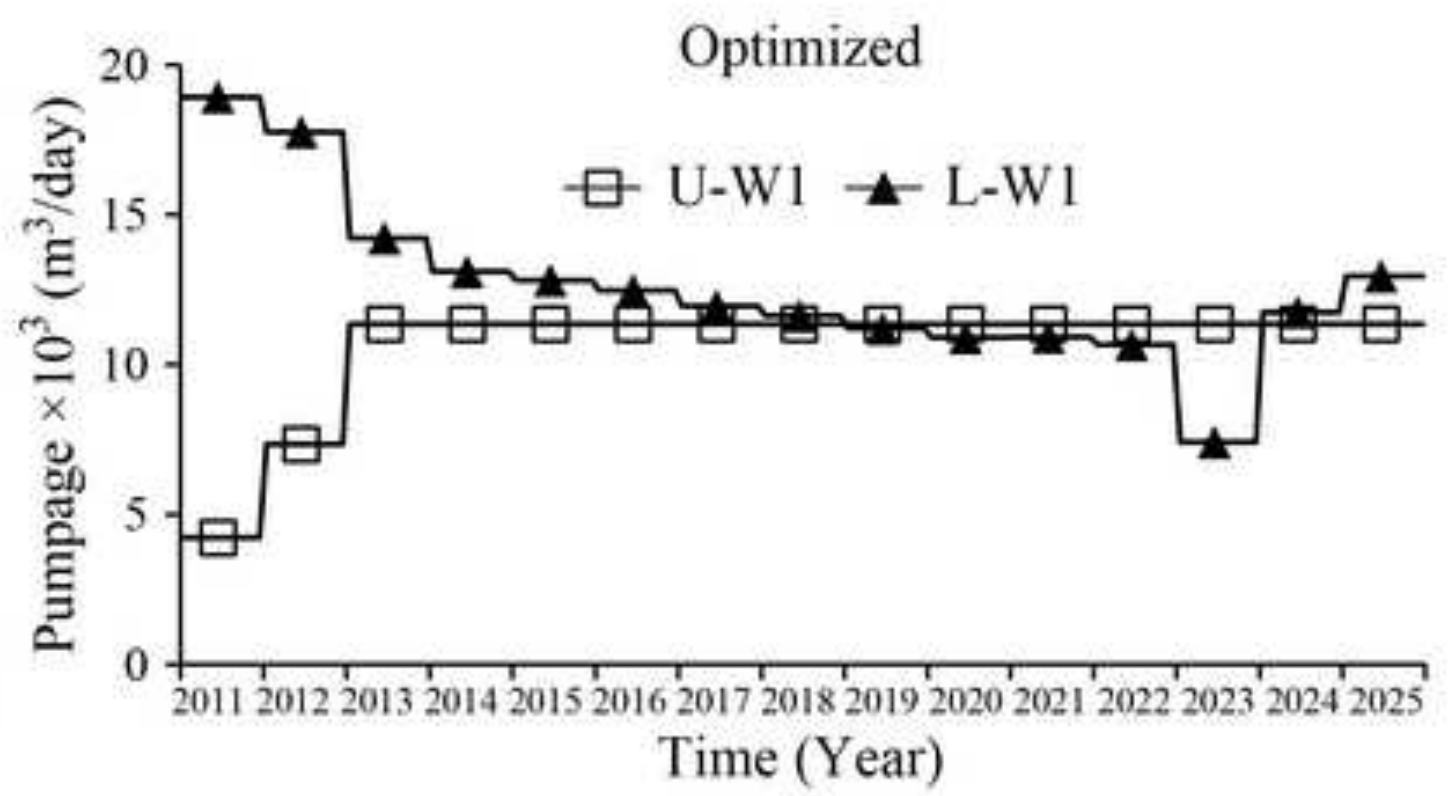

(d) 


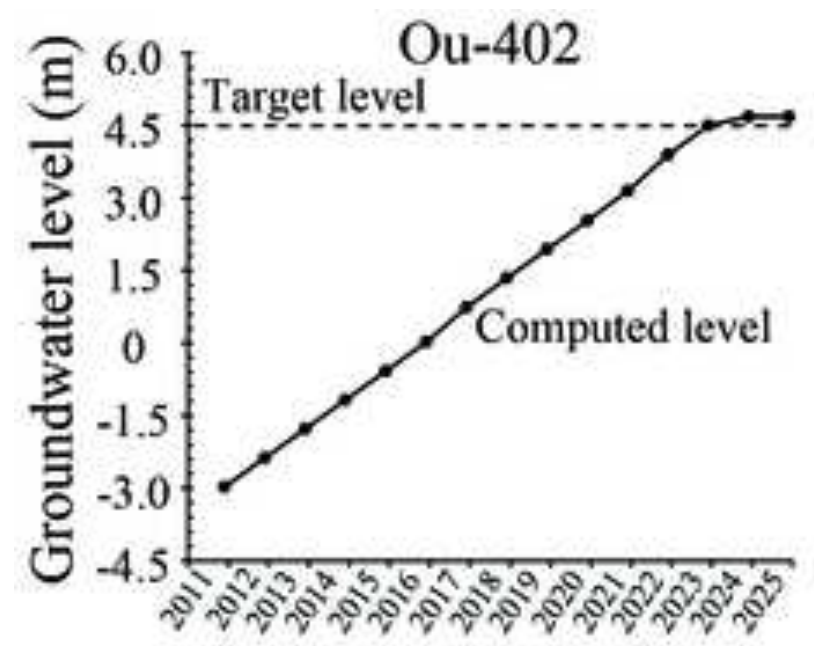

(a)

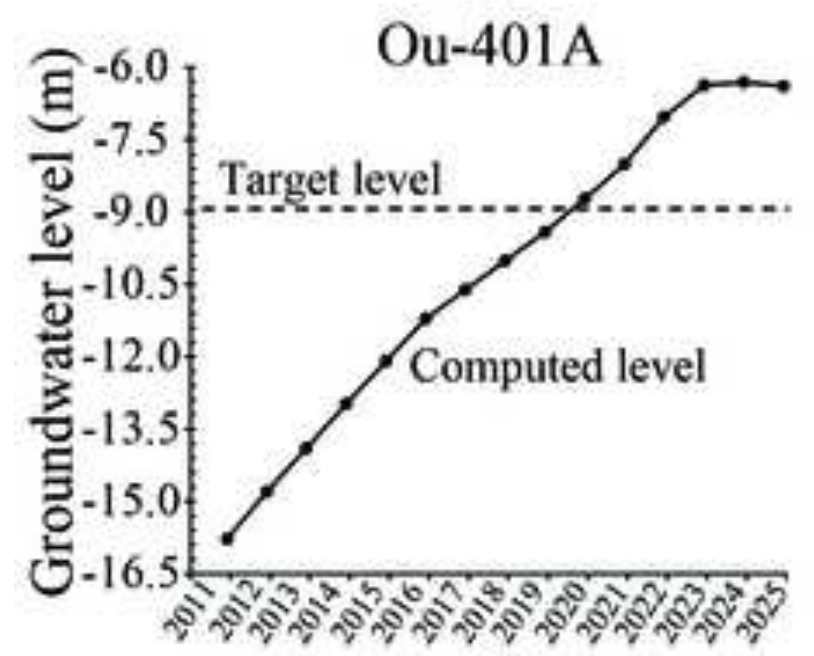

(d)

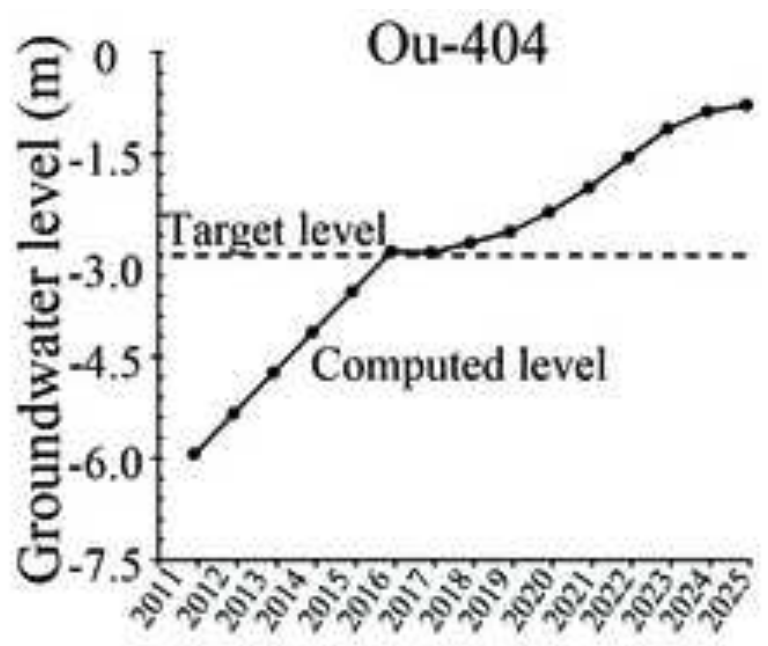

(b)

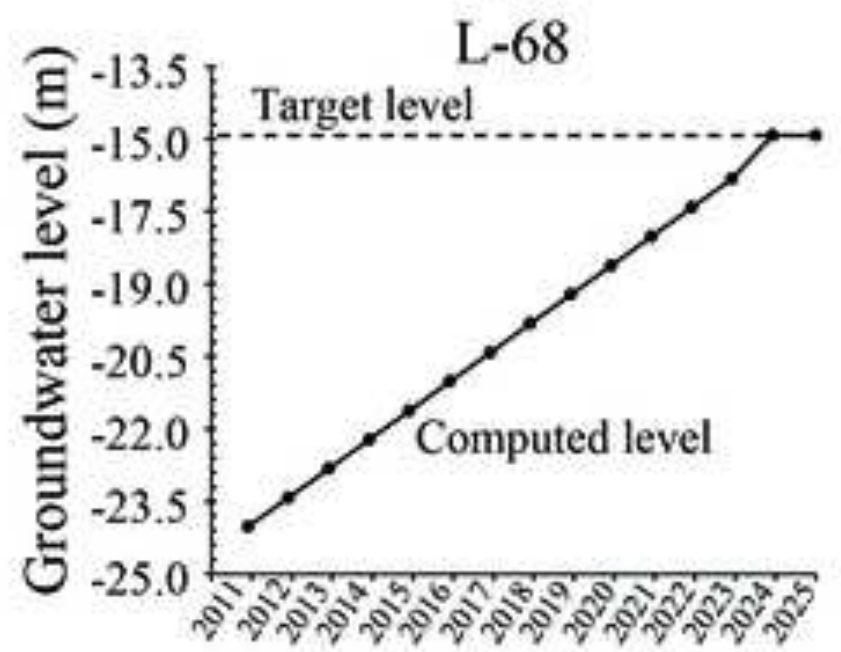

(e)

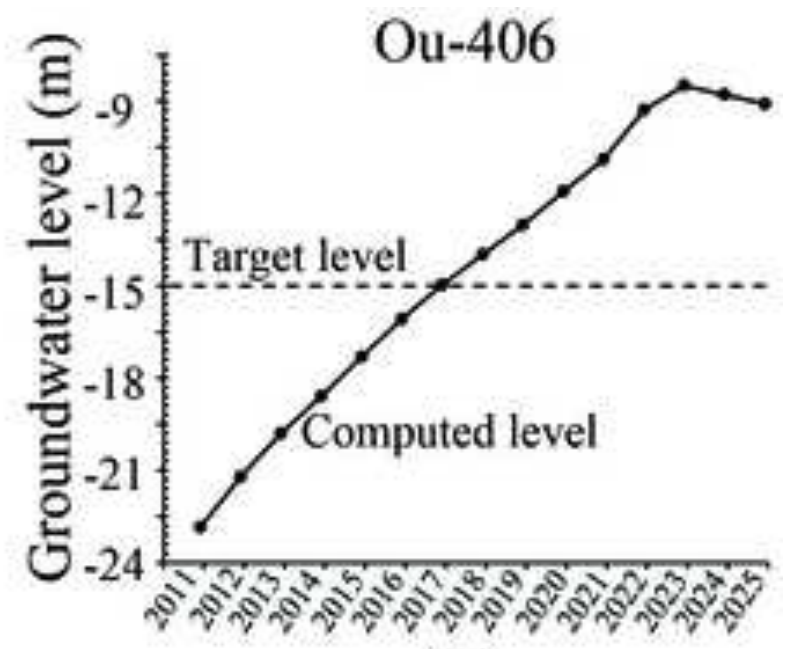

(c)

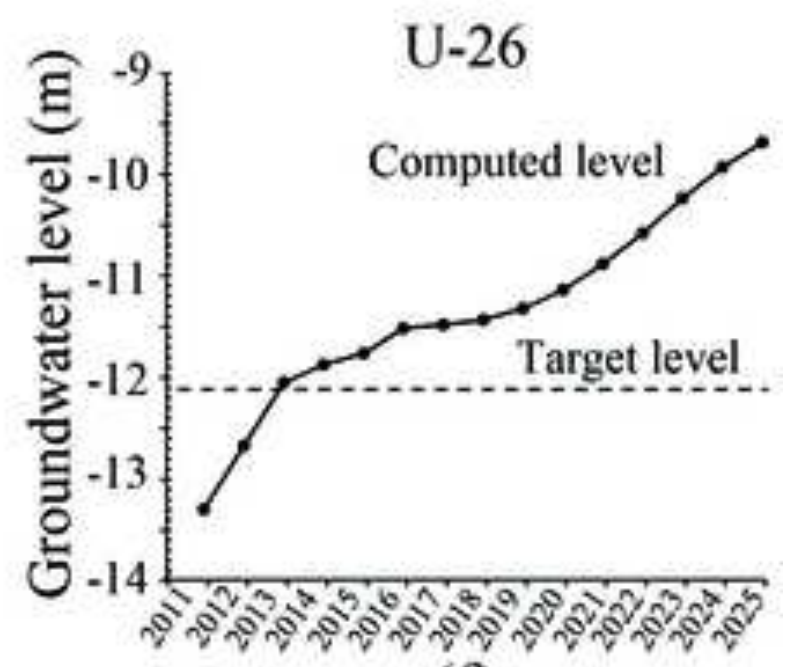

(f) 


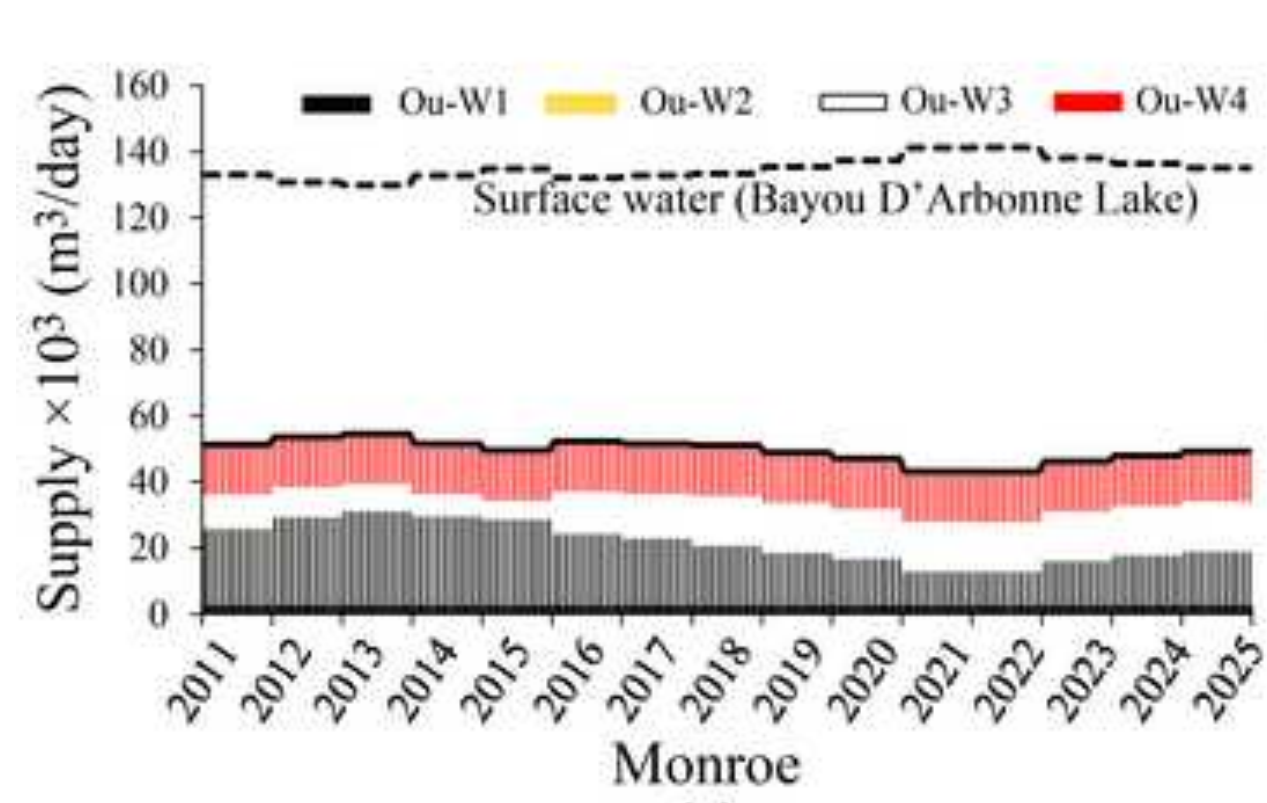

(a)

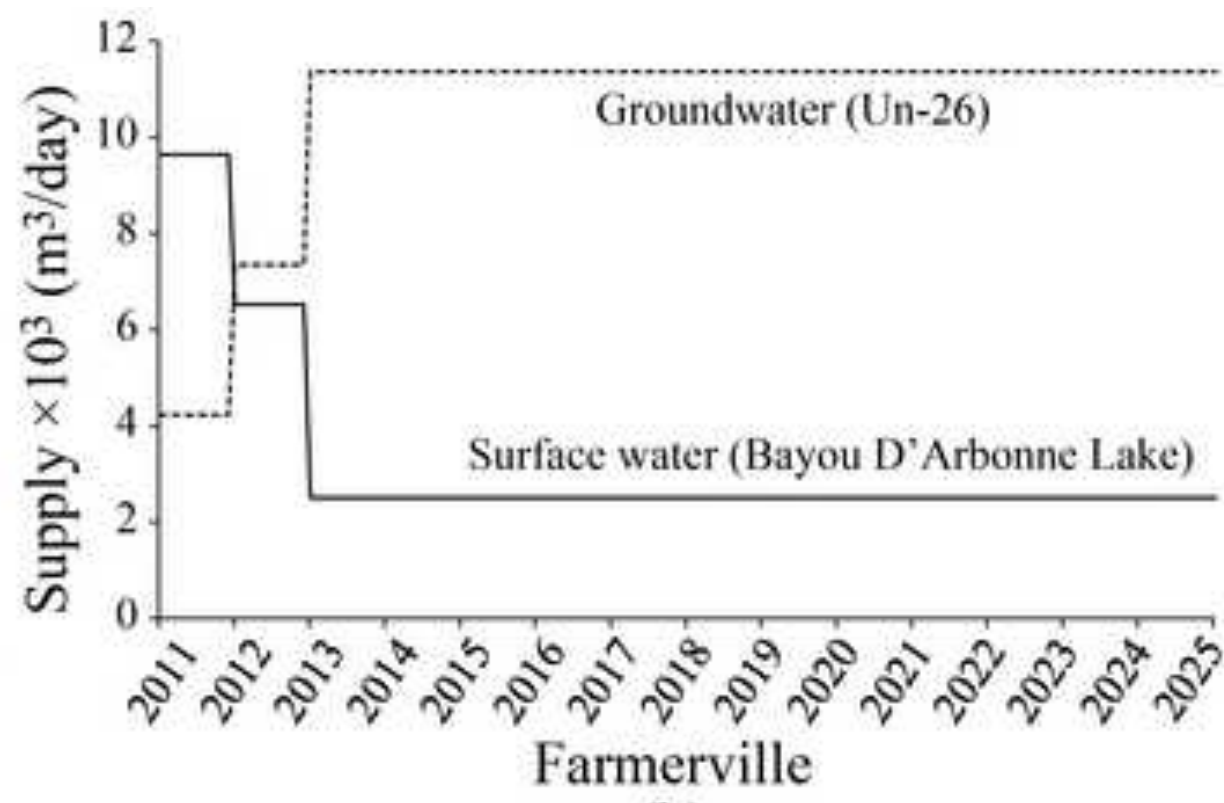

(b) 


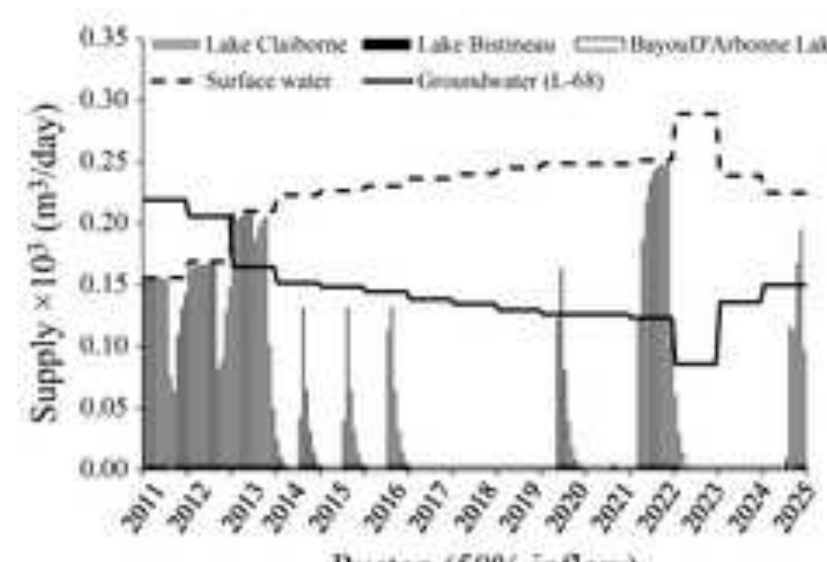

Ruston ( $50 \%$ inflow)

(a)

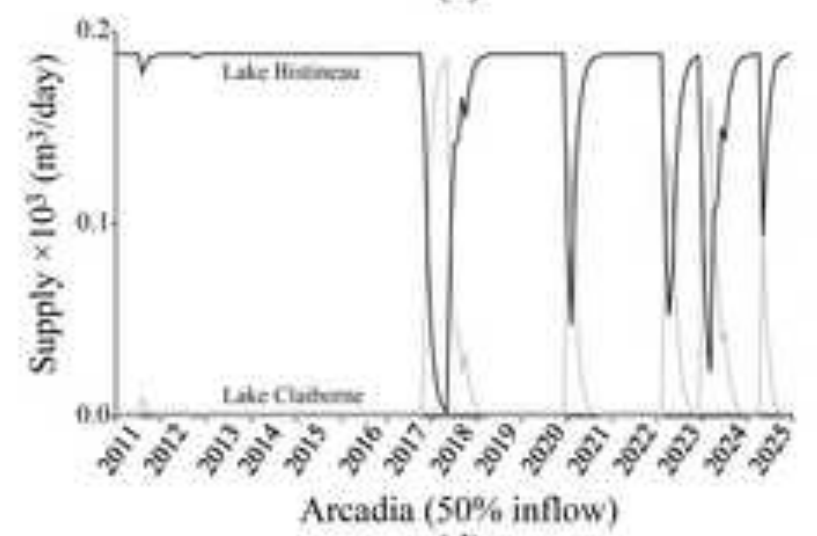

(d)

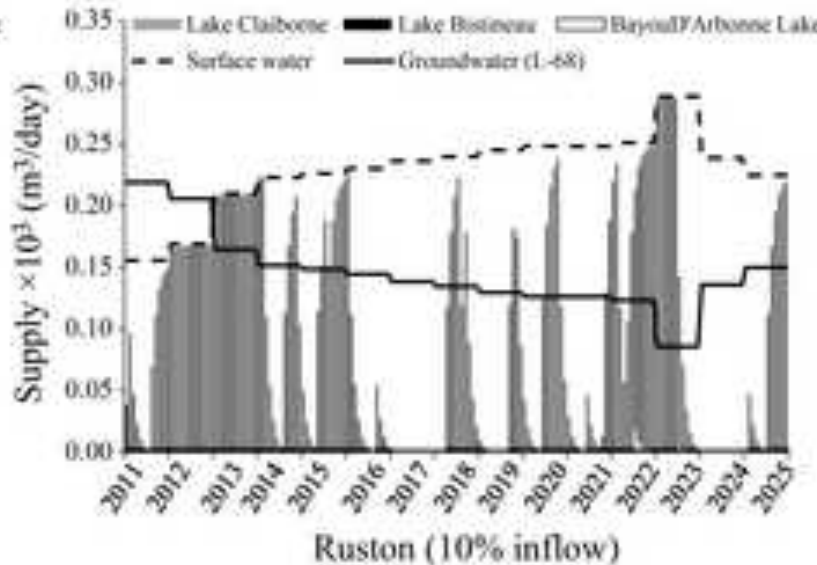

(b)

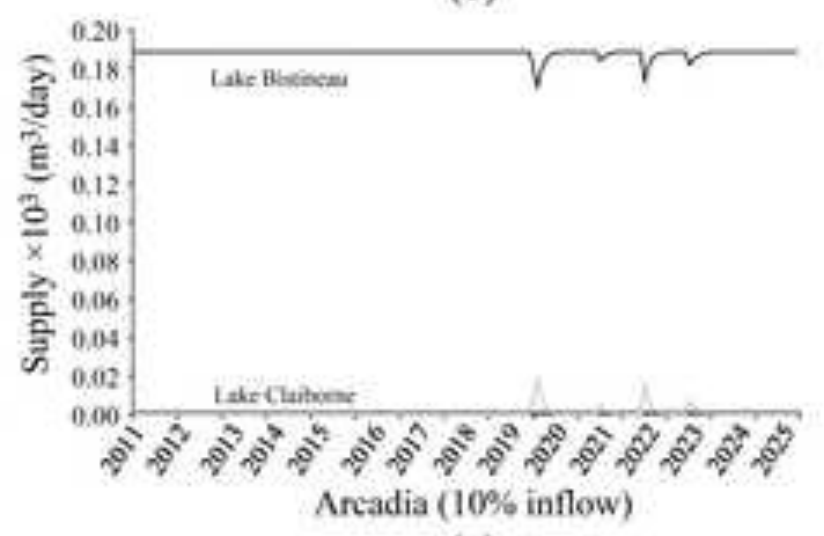

(c)

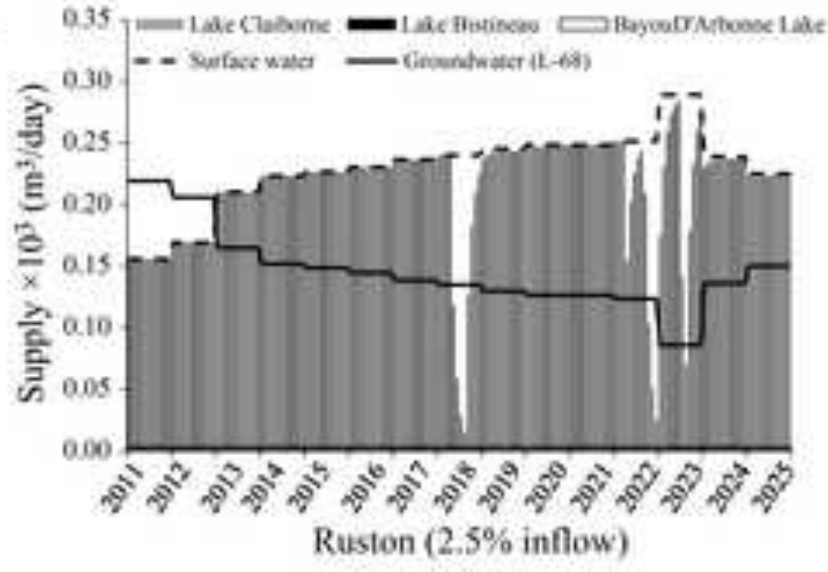

(c)

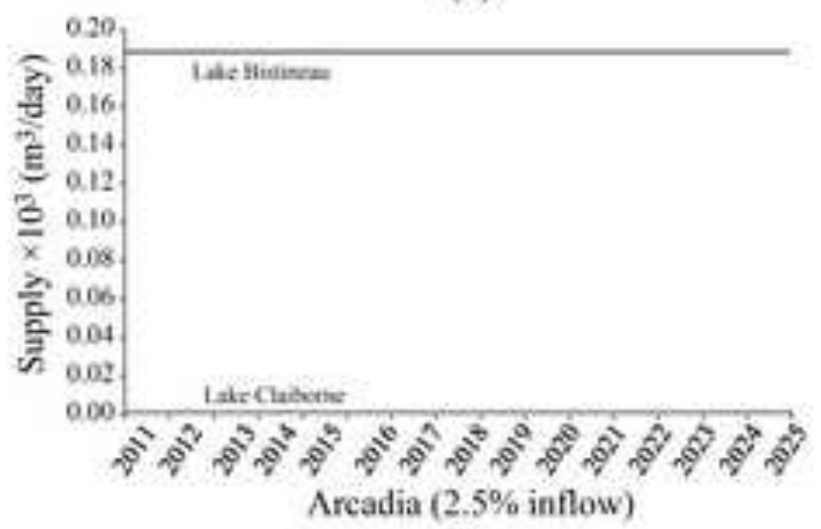

(f) 